\title{
Assessment of groundwater safety surrounding contaminated water storage sites using multivariate statistical analysis and Heckman selection model: a case study of Kazakhstan
}

\author{
Ivan Radelyuk (D) Kamshat Tussupova - Magnus Persson - Kulshat Zhapargazinova • \\ Madeniyet Yelubay
}

Received: 6 November 2019/Accepted: 30 July 2020/Published online: 8 August 2020

(C) The Author(s) 2020

\begin{abstract}
Petrochemical enterprises in Kazakhstan discharge polluted wastewater into special recipients. Contaminants infiltrate through the soil into the groundwater, which potentially affects public health and environment safety. This paper presents the evaluation of a 7-year monitoring program from one of the factories and includes nineteen variables from nine wells during 2013-2019. Several multivariate statistical techniques were used to analyse the data: Pearson's correlation matrix, principal component analysis and cluster analysis. The analysis made it possible to specify the contribution of each contaminant to the overall pollution and to identify the most polluted sites. The results also show that concentrations of pollutants in groundwater exceeded both the World Health Organization and Kazakhstani standards
\end{abstract}

I. Radelyuk $(\bowtie) \cdot$ K. Tussupova $\cdot$ M. Persson

Department of Water Resources Engineering, Lund

University, Box 118, 22100 Lund, Sweden

e-mail: ivan.radelyuk@tvrl.lth.se

I. Radelyuk $\cdot$ K. Tussupova

Center for Middle Eastern Studies, Lund University,

22100 Lund, Sweden

I. Radelyuk · K. Zhapargazinova · M. Yelubay

Department of Chemistry and Chemical Technology,

Pavlodar State University, 140000 Pavlodar, Kazakhstan

K. Tussupova

Kazakh National Agrarian University, 050010 Almaty,

Kazakhstan for drinking water. For example, average exceedance for total petroleum hydrocarbons was 4 times, for total dissolved solids -5 times, for chlorides -9 times, for sodium-6 times, and total hardness was more than 6 times. It is concluded that host geology and effluents from the petrochemical industrial cluster influence the groundwater quality. Heckman two-step regression analysis was applied to assess the bias of completed analysis for each pollutant, especially to determine a contribution of toxic pollutants into total contamination. The study confirms a high loading of anthropogenic contamination to groundwater from the petrochemical industry coupled with natural geochemical processes.

Keyword Kazakhstan - Petrochemical industry · Water quality · Principal component analysis · Cluster analysis - Heckman selection model

$\begin{array}{ll}\text { Abbreviations } \\ \text { Alk } & \text { Alkalinity } \\ \text { BTEX } & \text { Benzene, toluene, ethylbenzene and xylenes } \\ \text { CA } & \text { Cluster analysis } \\ \text { EPA } & \text { United States Environmental Protection } \\ & \text { Agency } \\ \text { EU } & \text { European Union } \\ \text { GW } & \text { Groundwater } \\ \text { km } & \text { Kilometers } \\ \text { KZ } & \text { Kazakhstan } \\ \mathrm{m} & \text { Meters }\end{array}$


PAH Polycyclic aromatic hydrocarbons

PC Principal component

PCA Principal component analysis

TDS Total dissolved solids

TH Total hardness

TPH Total petroleum hydrocarbons

UN United Nations

WHO World Health Organization

\section{Introduction}

Safe drinking water is one of the sustainable development goals announced by the UN; however, in many countries, the goal remains far off. In 2015, the distribution of global groundwater use was estimated to $50 \%$ for drinking purpose and $43 \%$ for irrigation (UNESCO 2015). Historically, groundwater quality has been deteriorated by human activities, such as agricultural, industrial, and urbanization processes (WHO 2006). In Kazakhstan, groundwater withdrawal amounted to $1.078 \mathrm{~km}^{3}$ in 2016 (UN 2019). One crucial problem in the country is toxic wastewater from petrochemical factories (Radelyuk et al. 2019), a very important factor in Kazakhstani economy. The oil refinery industry is represented by three large factories, and their capacity is estimated to be 360 thousand barrels daily with an annual growth of $2.9 \%$ (BP 2018). Additionally, refineries are associated with petrochemical industry. Industrial clusters are established around core refineries. It leads to growth of production and increasing level of contamination. The problem is that the current methods of wastewater treatment in the petrochemical sector, as well as the conditions of the treatment units built during the Soviet era, do not assure a safe level of contaminants concentrations for the ecological systems. Thus, the existing discharge system has a significant negative impact on the environment and could potentially become a health issue for the population.

The groundwater is the main source for decentralized and centralized drinking water supply in rural areas in Kazakhstan, where more than half of the population live (Zhupankhan et al. 2018; Bekturganov et al. 2016). The perceived water quality has been assessed in several research and showed relative satisfaction (Tussupova et al. 2015, 2016). However, in situ water quality and potential risk for groundwater safety have not been covered within existing scientific literature. Simultaneously, petrochemical plants in Kazakhstan continue to discharge wastewater with high concentrations of different pollutants and these contaminants may reach the groundwater very easily. Despite of existing system of ecological monitoring, oil refinery cluster in Kazakhstan is ranked as one of the biggest sources of water contamination by United Nations Economic Commission for Europe (UNECE 2019). Recent studies showed that approximately $1.5 \%$ of total deaths in Kazakhstan caused by waterborne diseases related to water pollution, including industrial sources (Karatayev et al. 2017).

While contaminated sites occupy relatively small area, they belong to larger aquifers and potentially cause serious hazard (Maskooni et al. 2020). The contaminated sites are considered as a serious problem worldwide (Kovalick and Montgomery 2017). Moreover, the situation becomes worse if governments deny any environmental pollution or the contaminated sites are not investigated (Naseri Rad and Berndtsson 2019). Research-based approach can deal with the situations and helps do right decisions about remediation programs and protect population and environment from related risks (Naseri Rad et al. 2020). Thus, it is urgent to identify the main sources of groundwater pollution from petrochemical industry in Kazakhstan in order to eliminate the risks.

Multivariate statistical techniques have been widely used for assessment of surface and ground water quality (Shrestha and Kazama 2006; Naseh et al. 2018; Cloutier et al. 2008; Ghahremanzadeh et al. 2018; Noori et al. 2010; Patil et al. 2020). The natural transformations happen due to saltwater intrusion, lithological/geochemical processes, rainfall and snowmelt, eutrophication processes. The anthropogenic invasion due to urban development, industrial and agricultural activities, influence by rural settlements significantly contributes to groundwater pollution, and consequently, affects the water quality. Thus, multivariate statistical techniques are efficient tools identifying and separating the main probable sources of pollution in the context of land-use changes. Three techniques are particularly common: Pearson's correlation, Principal Component Analysis and Cluster Analysis. Correlation matrix is used to determine potential interactions between different chemicals by pairwise variables comparison. PCA is used to identify 
statistically the most significant parameters, which are considered as major contributors to total contamination. Finally, CA combines similar groups of observations together. The techniques have been successfully applied, e.g., Egbueri (2019) divided his study area in Nigeria into insignificantly and highly polluted sites by using CA. Awomeso et al. (2020) investigated and identified possible sources of groundwater contamination such as leachate from septic tanks, nutrients from agricultural fields and chlorine pollution. The multiple natural and anthropogenic sources of surface and groundwater pollution have been presented by Omo-Irabor et al. (2008) in Nigeria. Impact on shallow groundwater in irrigated areas has been investigated by Trabelsi and Zouari (2019) in Tunisia. Shrestha and Kazama (2007) combined sites as less polluted, medium polluted and highly polluted, based on the similarities of water quality indicators in Japan. The same was for Kazi et al. (2009) who investigated the problem of water contamination by agriculture and industry in Pakistan. Liu et al. (2003) showed influence of processes of saltwater intrusion and arsenic pollution in Taiwan. Groundwater pollution sources apportionment in a land with high density of agriculture, industry and urbanization has been investigated in southwestern China ( $\mathrm{Li}$ et al. 2019). Hence, the multivariate statistical techniques let researchers successfully investigate certain case studies.

The aim of this paper is to analyse and interpret a dataset obtained during a 7-year (2013-2019) monitoring program of the wastewater discharge systems in one of the Kazakhstani industrial clusters. This dataset includes concentrations of substances in groundwater from nine observed wells surrounding the wastewater recipient. Kazakhstani law (Kazakhstan 2015) requires that strict standards for groundwater quality surrounding recipients are followed. If the requirements are neglected, the responsible company should take actions to eliminate the risks for the environment and people. Matrix correlation, PCA, and CA multivariate techniques were applied to (1) determine main pollutants with elevated concentrations in groundwater, (2) assess the contribution of each contaminant to temporal variations in groundwater quality and identify their potential origin, and (3) group the contamination sites affecting water quality and their potential sources by relevant similarities. The results contribute to the description of the spatial-temporal changes in groundwater quality of the study area. Heckman selection model was used to avoid bias of the results and look at specific properties of each pollutant more carefully. Moreover, the study highlights the main sources of contamination at the different locations of the study area and is thus of interest for local key stakeholders, groundwater modelling researchers, and risk analysis managers.

\section{Materials and methods}

Study area

The industrial site of this study belongs to the special economic zone and is located in the north-eastern part of Kazakhstan. The region is located in a sharply continental zone, where mean monthly temperatures range from $-19.3{ }^{\circ} \mathrm{C}$ in January to $+21.5^{\circ} \mathrm{C}$ in July, with an annual mean of $3.5^{\circ} \mathrm{C}$, absolute maximum of $+42{ }^{\circ} \mathrm{C}$ and absolute minimum of $-47{ }^{\circ} \mathrm{C}$. Annual precipitation is around $303-352 \mathrm{~mm}$, including $264 \mathrm{~mm}$ in liquid phase. The driest months are May, June, and July. Potential annual evaporation is around $957 \mathrm{~mm}$ (Heaven et al. 2007). Average relative humidity equals $82 \%$ and $45 \%$ for the coldest and the hottest period of the year, respectively. 70-85 days of the year is represented with the humidity $80 \%$ and more.

The recipient pond (Fig. 1) is based on a natural bitter-salty pond for receiving and storing biologically treated wastewater from the nearby located petrochemical industry. According to Kazakhstani legislation (Kazakhstan 2012), this pond is not a source for drinking, domestic and irrigation water. The annual volume of received wastewater amounted to 1.63-2.21 million $\mathrm{m}^{3}$ for the period 2009-2019, instead of designed 4.12 million $\mathrm{m}^{3}$. The water volume and water surface for the same period are maintained within 3.6-6.7 million $\mathrm{m}^{3}$ and $2.45-3.73 \mathrm{~km}^{2}$, respectively, instead of the designed 23.5 million $\mathrm{m}^{3}$ and $5.23 \mathrm{~km}^{2}$, respectively. Observation wells are located out of barrier for groundwater quality monitoring and belong to permanent control from governmental bodies. The installation procedures followed appropriate installation technique in case of required installation materials and methods and planning of the location of the monitoring system (Houlihan and Lucia 1999). The depth of the wells 


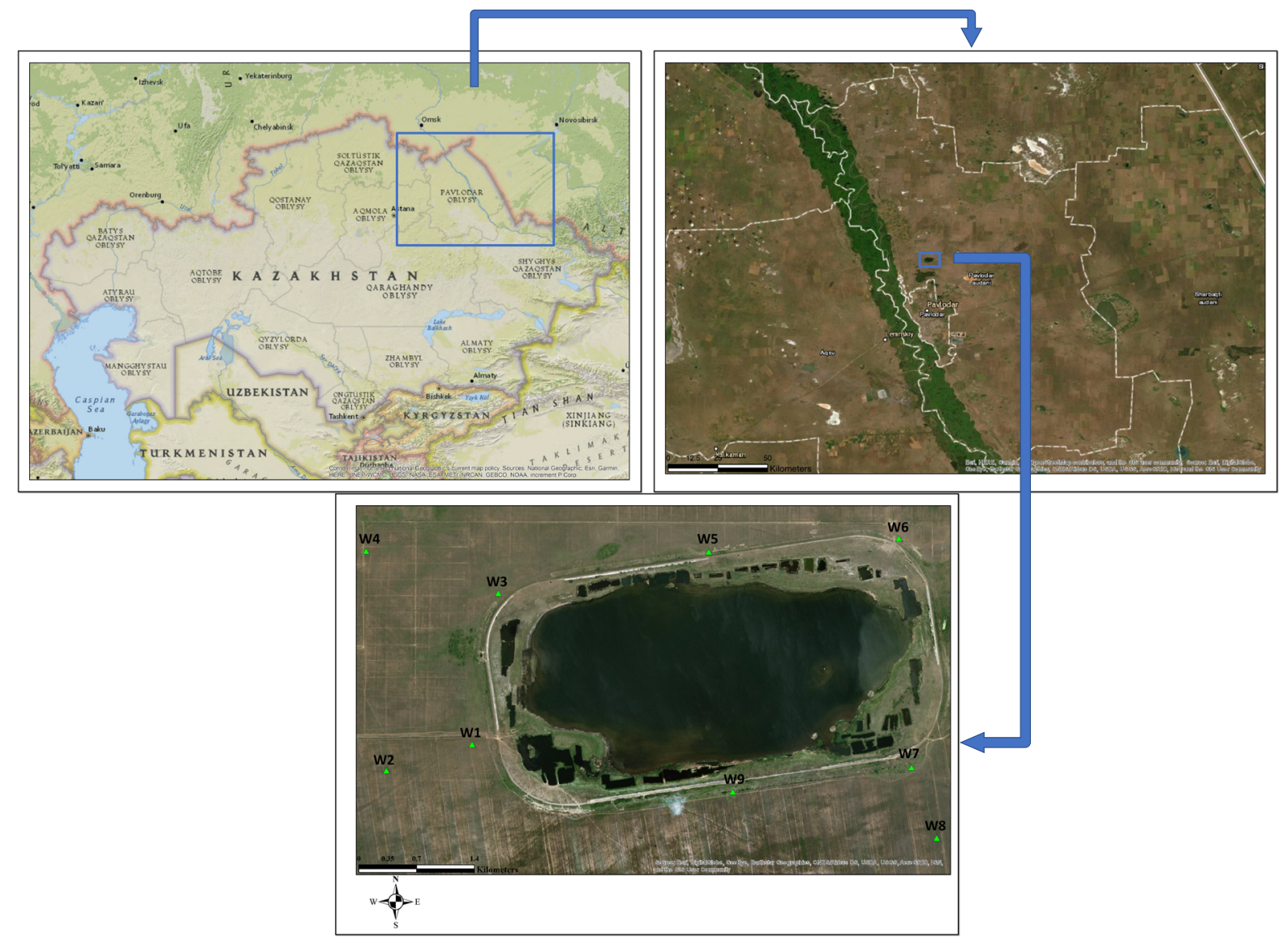

Fig. 1 Study Area. Green triangles show location of wells sampled

varies between 10.1 and $24.6 \mathrm{~m}$ below ground level. The groundwater depth in the wells varied between 1.1 and $4.9 \mathrm{~m}$.

The hydrogeological conditions of the study area have been poorly investigated during soviet and postsoviet periods. The geological cross-section is represented by four geologic-genetic layers: contemporary sediments (land cover), upper-quarternary and contemporary aeolian-deluvial deposits (clayey sand) and upper-quarternary alluvial deposits (loam and/or fine to medium-grained sands). The geological profiles of the examined wells are presented in Fig. 2. Groundwater is represented by two aquifers: shallow unconfined and confined aquifers. The upper aquifer is composed of clay-sand and mixed size sands. The bottom of the aquifer lays on the depth 8.0-24.0 m below surface level. The aquifer is mainly recharged from water infiltration from the surface. The discharge is partly due to evapotranspiration and partly due to percolation to the underlying aquifer. Amplitude of seasonal fluctuation of groundwater table is about $0.7 \mathrm{~m}$ (Fig. 3). The figure shows that the GW level has peak values after the winter during the snowmelt season and after that reaches its minimal values during the summer. Interpolation using inverse distance method was used to establish GW flow direction and the bottom of the first aquifer. Figure 4 shows a contour map of the groundwater level and the elevation of the bottom of the unconfined aquifer. The second aquifer composed of medium-grained and small-grained sands. It is recharged from the head water and from the upper aquifer. The aquifer discharges to the nearest river, which is located $4 \mathrm{~km}$ west from the pond.

A total of 117 groundwater samples from the shallow aquifer were collected and analyzed between 2013 and 2019, from all observation wells. Sampling was made two times per year, in spring and autumn. 

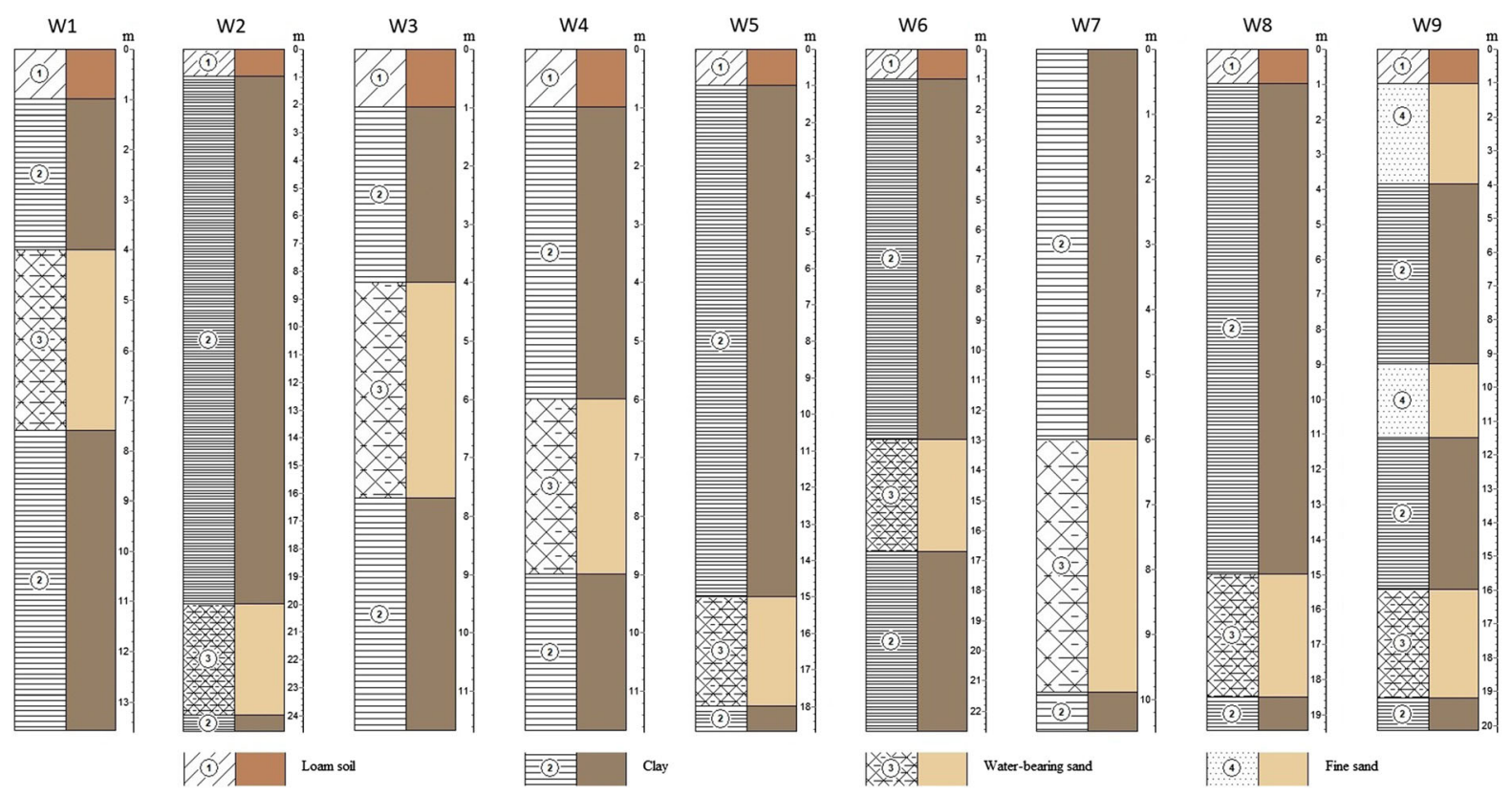

Fig. 2 Geological profiles of the examined wells

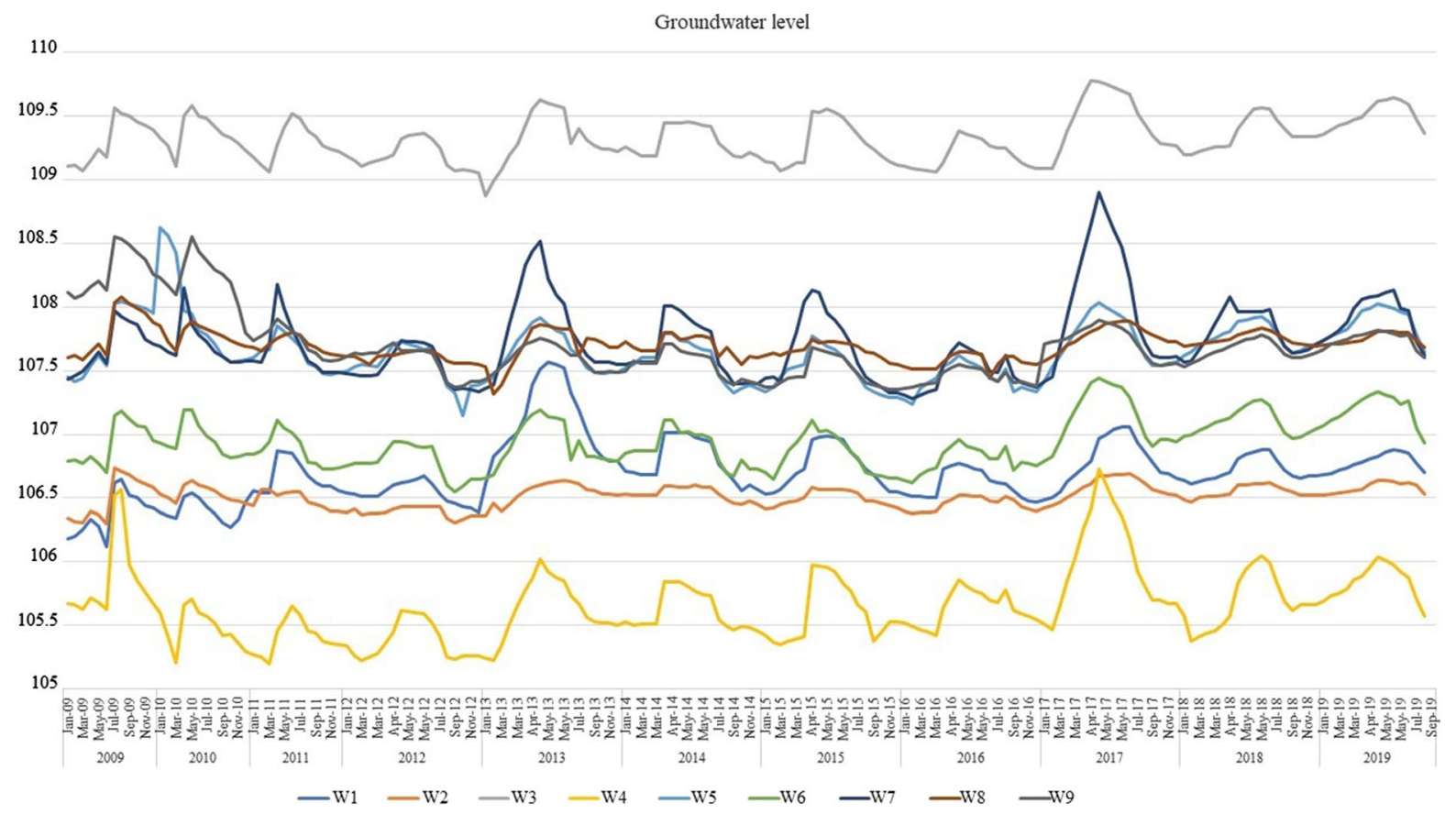

Fig. 3 Seasonal fluctuations of groundwater level in the nine wells

The groundwater depth was measured regularly from March to November each year. The procedures of the sampling and measurements are controlled by Kazakhstani legislation from the sufficient international standards (Houlihan and Lucia 1999). Before sampling, the groundwater in the well was evacuated several times (usually, three times) by pumping. The pumping equipment was also flushed prior to sampling 

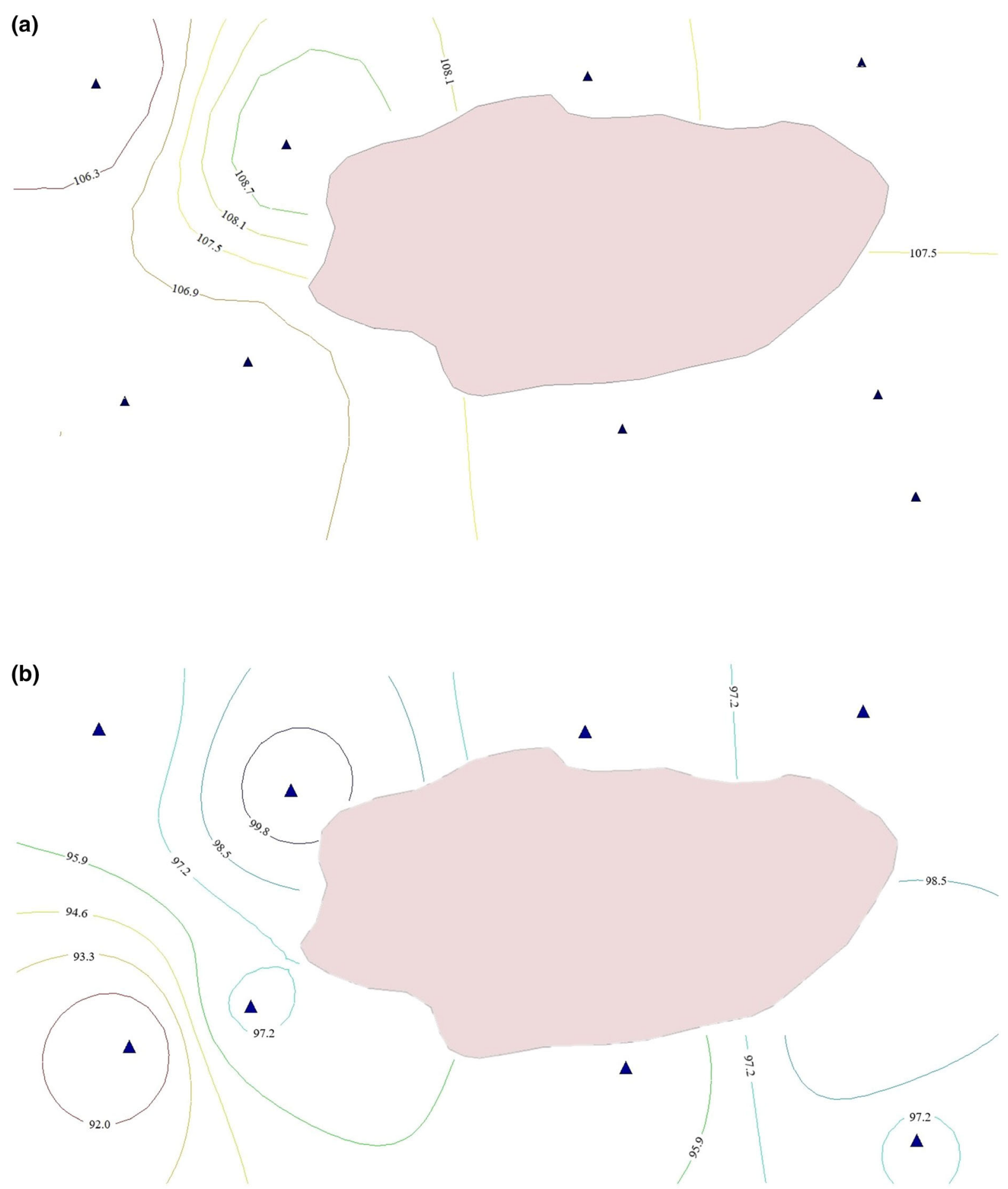

Fig. 4 a Contour map of groundwater levels on the study area, b Spatial distribution of the bottom of the first aquifer

to avoid unwanted pollution. After establishing a static water level, the sampler was immersed to a depth below the water table by $0.5 \mathrm{~m}$ or less. Water samples were collected in 1-1 dark glass bottles. The vessels were moved into a transportable fridge for immediate delivery and analysis to the licensed factory 
laboratory. Extra samples were collected for the analysis of metals with acidification by $\mathrm{HNO}_{3}$.

\section{Multivariate statistical techniques}

Correlation analysis, principal components analysis (factor analysis), and hierarchical cluster analysis were applied to identify the multivariate relationships between different variables and samples in the study area. The dataset was normalized for elimination of the effect from differences in units (Eq. 1).

$Z_{i j}=\frac{\left(x_{i j}-m_{i}\right)}{\mathrm{SD}}$,

where $Z_{i j}$ are normalized values from $x_{i j}, i$ is represented variables, $j$ is the sample number, $m_{i}$ is the mean value and SD is the standard deviation of the sample.

The relation between each pair of variables was measured by Pearson's correlation coefficient to determine the geochemical associations among different variables. Correlation coefficients greater than 0.5 were considered significant. PCA recognizes the most significant parameters from a big dataset of intercorrelated parameters and created independent variables (Eq. 2).

$z_{i j}=a_{i 1} x_{1 j}+a_{i 2} x_{2 j}+\cdots+a_{i m} x_{m j}$,

where $z$ is the component score, $a$ is the component loading, $x$ is the measured value of variable, $i$ is the component number, $j$ is the sample number and $m$ is the total number of variables. Factor analysis (FA) is a similar technique as PCA. However, PC is presented as a linear combination of parameters. FA follows PCA and takes into account unobservable, hypothetical, and latent variables. They are included in equation with the special residual term (Eq. 3).

$z_{i j}=a_{f 1} f_{1 j}+a_{f 2} f_{2 j}+\cdots+a_{f m} x_{m j}+e_{f i}$,

where $z$ is the measured variable, $a$ is the factor loading, $f$ is the factor score, $e$ is the residual term according to errors or other source of variation, $i$ is the sample number and $m$ is the total number of factors.

Cluster analysis was used to assemble similar groups of observed wells due to similarities between their variables. Hierarchical agglomerative CA provided Ward's linkage distance, reported as $D_{\text {link }} / D_{\text {max }}$, which represents the quotient between the linkage distances for each case divided by maximal linkage distance. Produced dendrogram lets to analyse similarities easily. Ward's linkage, the Euclidean distance as similarity measurements, and Q-mode are usually used for cluster analysis for assessment of groundwater quality (Egbueri 2019; Cloutier et al. 2008; Kazi et al. 2009; Awomeso et al. 2020; Trabelsi and Zouari 2019; Amanah et al. 2019; Bouteraa et al. 2019).

\section{Heckman selection analysis}

Heckman selection analysis, to the authors' knowledge, has never been applied to assess the environmental characteristics. This type of analysis was adapted from the original work of Heckman in the economical science (Heckman 1979) and from the application this type of this method in other fields, for example in the assessment of energy production (Sun et al. 2014), urban transportation research (Kaplan et al. 2016) and estimating crash rate (Xu et al. 2017). The method in this study is used to assess unobservable variables, that potentially impact on the total contamination rate. Gadgil investigated the list of chemicals in the WHO guidelines (Gadgil 1998) and concluded that certain chemicals have no strong requirements for their concentrations in drinking water, as the exposure of exceeded concentrations for human health is not significant. The idea of this assessment is not just looking at several contaminants and their concentrations, but also to consider and evaluate other important factors such as location of the sampled value, percent of exceeding of the certain contaminant and individual characteristics of the contaminant. Selected variables were divided into two categories. First: chemicals seriously affecting health (rated as sanitary toxic due to Kazakhstani standard (Kazakhstan 2015)); second: other hazardous materials (rated as non-toxic). It is aimed to compare potential effect of toxic and non-toxic contaminants. We focused, on the one hand, on several pollutants with elevated concentrations, such as chlorides or sulfates, which are not rated as significant impact on health, but can be dangerous for other cases, for instance, for corrosion of pipes, or for irrigation properties of soil; on the other hand, on the contaminants, rated as dangerous for the health, or toxic (for example, hardness or petroleum hydrocarbons).

This model includes two-step equation, which is assumed as an advanced regression model equation: 


$$
Y_{i}=\beta_{1} S_{i}+\beta_{2} X_{i}+u_{i},
$$

where $Y_{i}$ is considered as total contamination, $S_{i}$ represents the concentration of chemicals, and $X_{i}$ shows several contaminants as a set of control variables. The effect of the exceeded concentrations on the total contamination is given by the parameter $\beta_{1}$. Parameter $i$ represents each individual observation.

Equation (4) does not consider other potentially important independent variables which can affect for final result. For example, it could be locations of the wells or individual characteristics of different contaminants such as their toxicity and exposure level in case of influence of chemicals for people's health. There could be a different input of high exceeding of non-toxic contaminant and low exceeding of toxic contaminant. Second one would be much more dangerous for health. Thus, more attention should be paid to the level of toxicity. Specific description of this equation can be written as:

$$
\begin{aligned}
Y_{i}^{*} & =\beta_{1} S_{i}+\beta_{2} X_{i}+u_{i} \\
D_{i} & =1\left(\gamma_{1} S_{i}+\gamma_{2} Z_{i}+v_{i}>0\right), \text { and } \\
Y_{i} & =Y_{i}^{*} D_{i},
\end{aligned}
$$

where $\left(Y_{i}, D_{i}, S_{i}, X_{i}, Z_{i}\right)$ are observed random variables and 1(.) is an indicator function. The first equation represents the total contamination of all contaminants. The second equation is the selection equation, where $D_{i}$ is added as a dummy variable indicating whether value $i$ represents a measurement of toxic/non-toxic pollutant. A set of variables $Z_{i}$ includes additional parameter such as a well value $i$. Set of control variables $Z_{i}$ must include at least one variable which is not included in $X_{i}$ (Sartori 2003).

All mathematical and statistical computations were performed using Microsoft Office Excel 2016, IBM SPSS Statistics 26 software and STATA 15.0 (StataCorp LP).

\section{Results and discussion}

\section{Groundwater quality parameters}

Table 1 presents the results of measurements of groundwater quality from the wells surrounding the recipient pond. Kazakhstani and WHO standards for drinking water were used for assessing all parameters.
The concentrations of several parameters in wastewater, which are discharged into the recipient pond, are also presented in the table. Those characteristics came from the previous publication of the authors (Radelyuk et al. 2019).

As shown, all wells had exceeding concentrations of total petroleum hydrocarbons (see also Fig. 5). When the permissible concentration of TPH is $0.1 \mathrm{mg} /$ $\mathrm{L}$, the concentrations of TPH varied between 0.08 and $1.20 \mathrm{mg} / \mathrm{L}$ with mean value $0.42 \mathrm{mg} / \mathrm{L}$, which exceeded the norm 4 times. Although low concentrations of TPH in water might be considered harmless, researchers found that long-term exposure to TPH causes carcinogenic diseases (Pinedo et al. 2013; Wake 2005). Table 1 also shows that dangerous concentrations of phenols were identified in all nine wells. This pollutant had been evaluated as very toxic and was included in the list of priority pollutants by Environmental protection agency (EPA 2012). The number of disorders has been discovered by acute exposure of phenol: muscular convulsions, hypothermia, muscle weakness and tremor, collapse, coma, etc. (Nair et al. 2008). There is a limitation in the assessment of the presence of phenol in our case study. However, the limit of the concentration of simple phenol (phenol index) is $0.25 \mathrm{mg} / \mathrm{L}$ according Kazakhstani standard. The same value is established in the standard of the factory for the observed wells (Radelyuk et al. 2019). At the same time, protocols of GW quality measurements name this parameter "volatile phenols". This type of phenolic compound is considered to be limited $0.001 \mathrm{mg} / \mathrm{L}$. Thus, there is unclear situation of what limit should be used. Measured TDS values exceeded the KZ and WHO maximum permissible levels of $1000 \mathrm{mg} / \mathrm{L}$ in most cases on average five times (Fig. 5). Further, the total hardness in the groundwater samples ranged between 2 and $390 \mathrm{mmol} / \mathrm{L}$ with mean exceeding the standard six times (Fig. 5). According the Todd classification, almost all samples might be categorized as very hard water. Hard water may cause cerebrovascular and cardiovascular diseases (Stambuk-Giljanovic and Stambuk 2005). The chloride ion presence were between 56 and $24,757 \mathrm{mg} / \mathrm{L}$, with most samples elevated WHO's $250 \mathrm{mg} / \mathrm{L}$ recommended limit (exceeding 9 times on average) (Fig. 5). There are possible health-related concerns regarding $\mathrm{Na}^{+}$content in the groundwater because the mean elevated concentrations in the wells were six times over the 


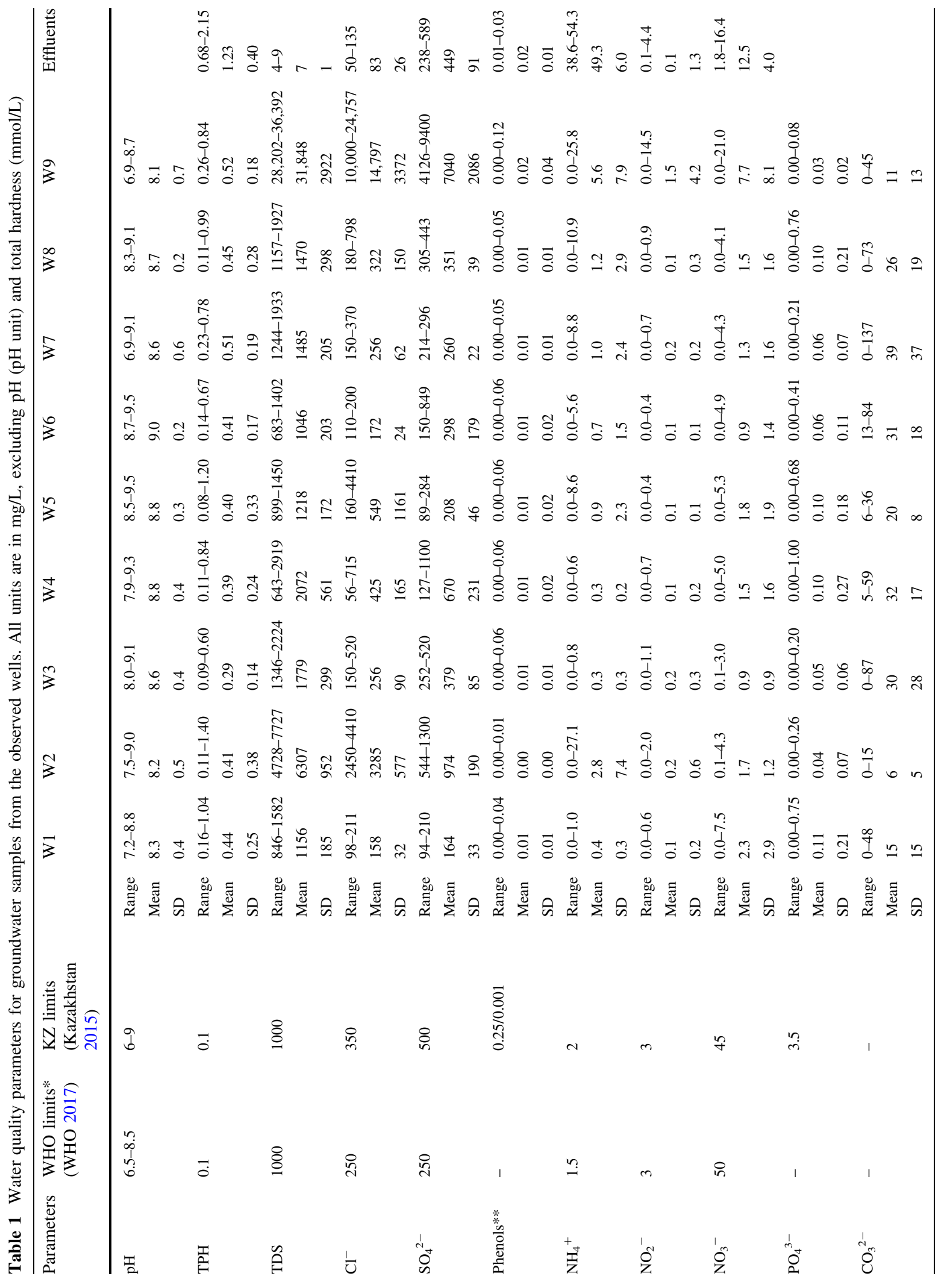




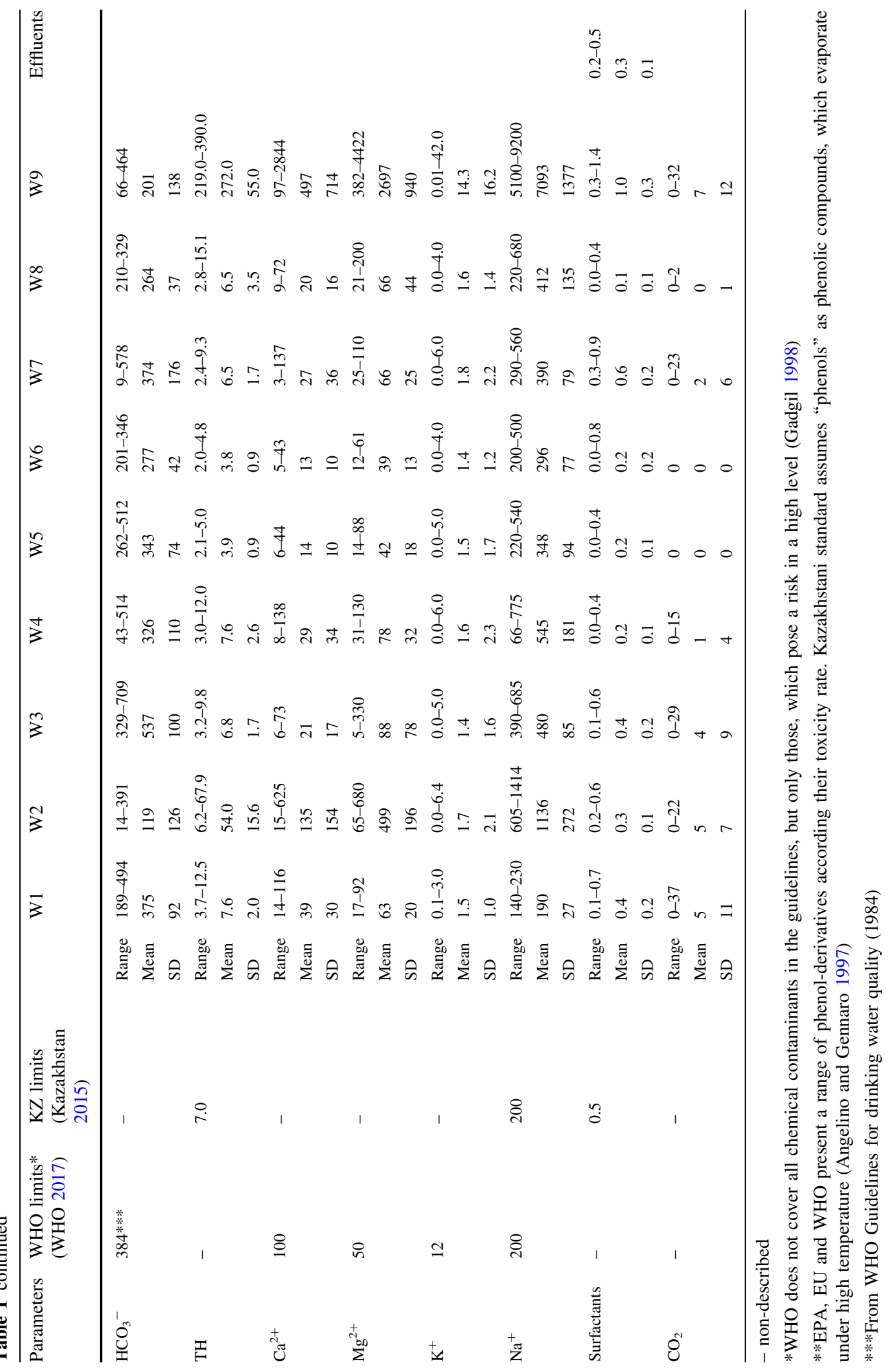



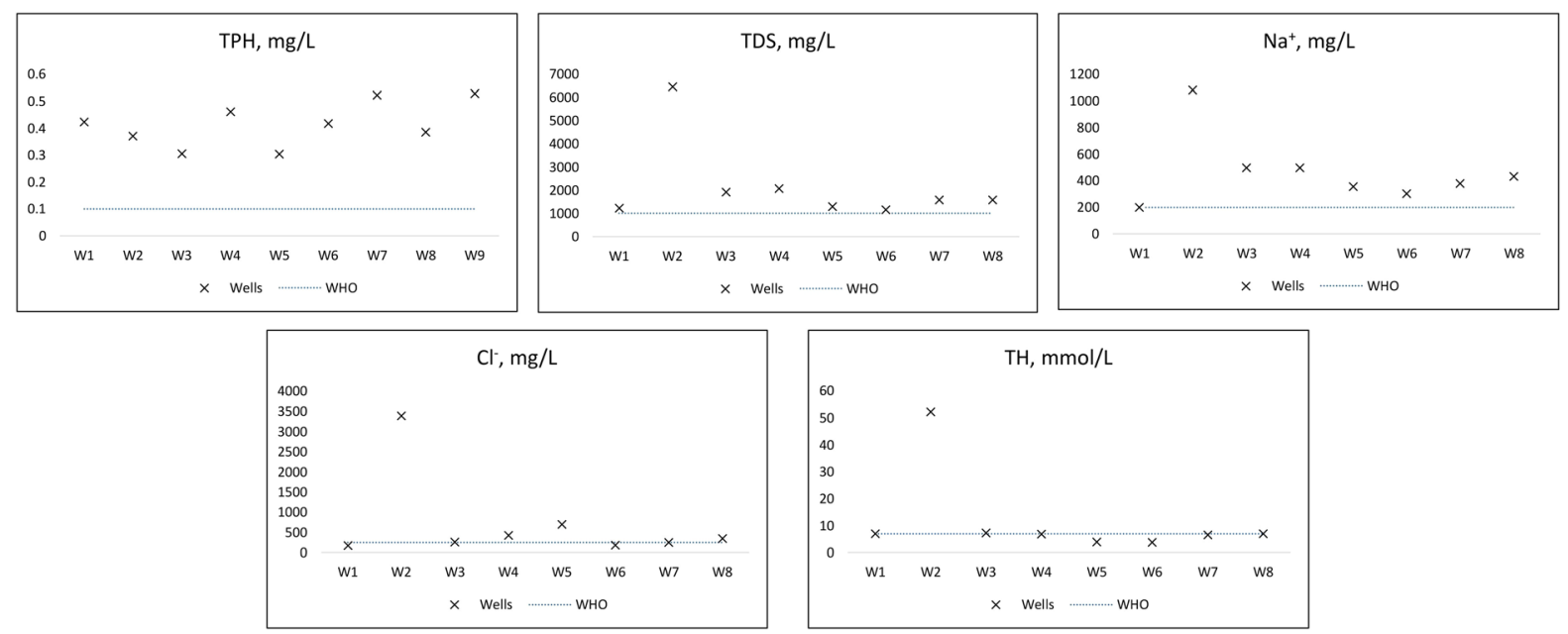

Fig. 5 Concentrations of some chemicals in the groundwater wells compared to WHO limits

permissible KZ limits and WHO indirect recommendation (Fig. 5). Consumption of high amount of sodium has been correlated with cardiovascular disease, such hypertension and stroke (Lucas et al. 2011). Finally, individual exceedings of surfactants were identified. Such high level of surfactants is related to several potential problems. The presence of some surfactants in connection with other contaminants may decrease the biodegradation rate of contaminant or stops the process at all. In other cases, the presence of the surfactants enhances the biodegradation rate. The desirable result is not clear without knowing the role of the surfactant participating the biodegradation process in a given remediation plan (West and Harwell 1992). Moreover, special focus should be paid to Well 9 which had extremely high values. For example, TDS had a value 37 times above the limit, chloride 99 times higher than limit, sulphate exceeded the limit 38 times, total hardness with associated cations by 56 times as well as highly elevated concentrations of ammonia, nitrites, nitrates, potassium, sodium and surfactants (Table 1). This is the reason why Fig. 5 does not include Well 9 presenting the concentrations of some chemicals comparatively with WHO recommendations.

The water containing such levels of those substances would normally be rejected by consumers. Additional epidemiological research should be provided in municipalities nearby the area of pond to assess potential connections between the high concentrations of some parameters, such as TPH, phenols,
$\mathrm{Na}^{+}, \mathrm{Cl}^{-}, \mathrm{SO}_{4}{ }^{2-}$, TDS and TH and cardiovascular and oncological diseases in the region.

Figure 6 shows temporal distribution of some chemicals. The $\mathrm{pH}$ values (Fig. 6a) normally were highest during the spring, while the value for W9 differs significantly and instead shows the lowest values during the same period. It could be explained by influence of recharge of snowmelt and geological characteristics of the area. The same situation can be applied for TPH. All wells show the highest concentrations of TPH during the spring (Fig. 6b). Moreover, the graphs mainly tend to raise their fluctuations and display an increasing trend. It potentially says that the pollution problem is growing in the area. Figure $6 \mathrm{c}$ represents the fluctuation of TDS in the groundwater. There are relatively flexible lines without significantly extremal changes.

Spatial distribution of the chemicals is presented in Fig. 7. pH values (Fig. 7a) are more than 7 for all wells, defining groundwater alkaline. According to Hem (1970) dissociation of carbonate and carbonate salts is a dominant process in nature, which leads to $\mathrm{pH}$ above 7. The maximal value of $\mathrm{pH}$ is found in well 6 , and minimal value belongs to the wells 2 and 9. Piper diagram is widely used to show the dominant hydrogeochemical faces (Piper 1944). The Piper plot (Fig. 8) verifies the direct relationships between the hydrochemical regime of groundwater in the area and the $\mathrm{pH}$ value. Total petroleum hydrocarbons have a maximal value in the well 9 and minimal in the well 3 (Fig. 7b). There are plotted only TDS, instead of TH, 
(a)

$$
\mathrm{pH}
$$

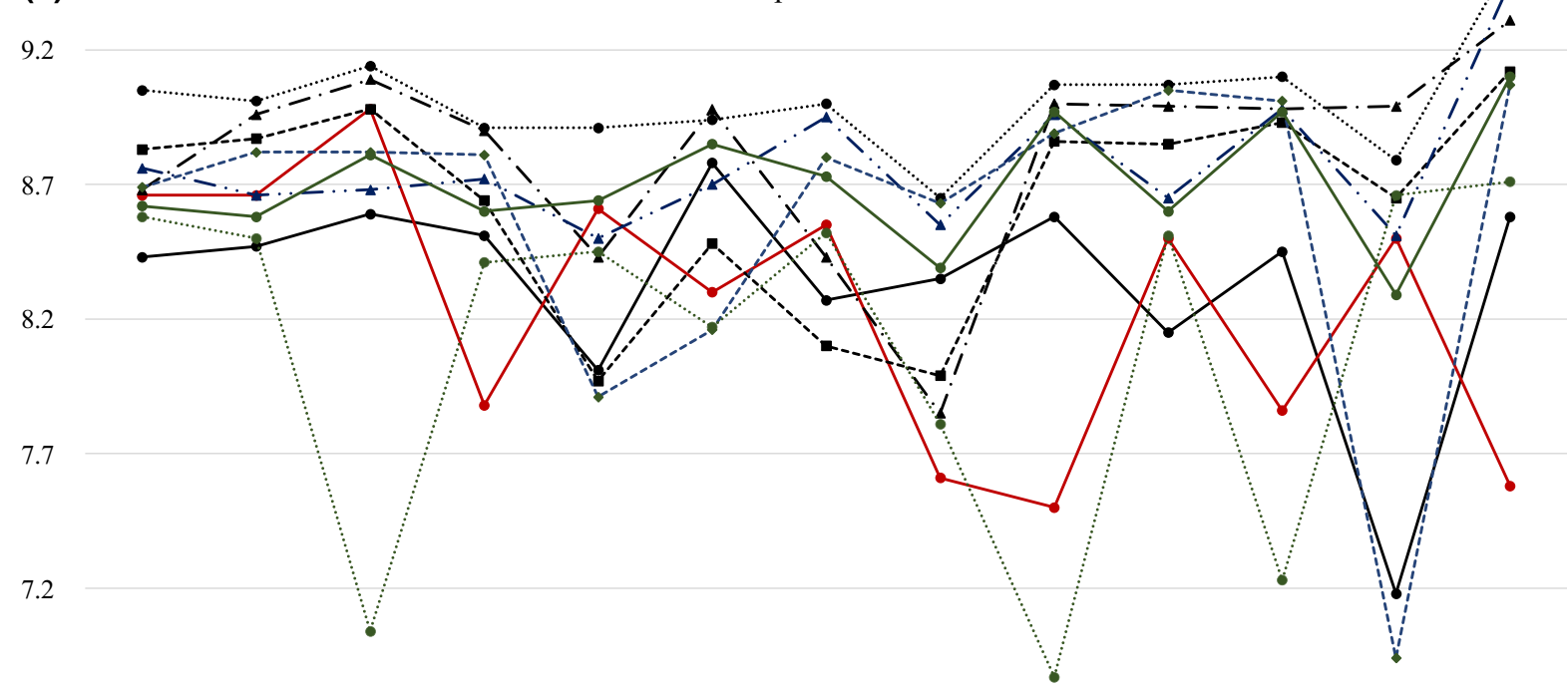

6.7

Autumn 13 Spring 14 Autumn 14 Spring 15 Autumn 15 Spring 16 Autumn 16 Spring 17 Autumn 17 Spring 18 Autumn 18 Spring 19 Autumn 19

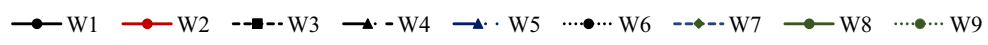

(b)

$\mathrm{TPH}, \mathrm{mg} / \mathrm{L}$

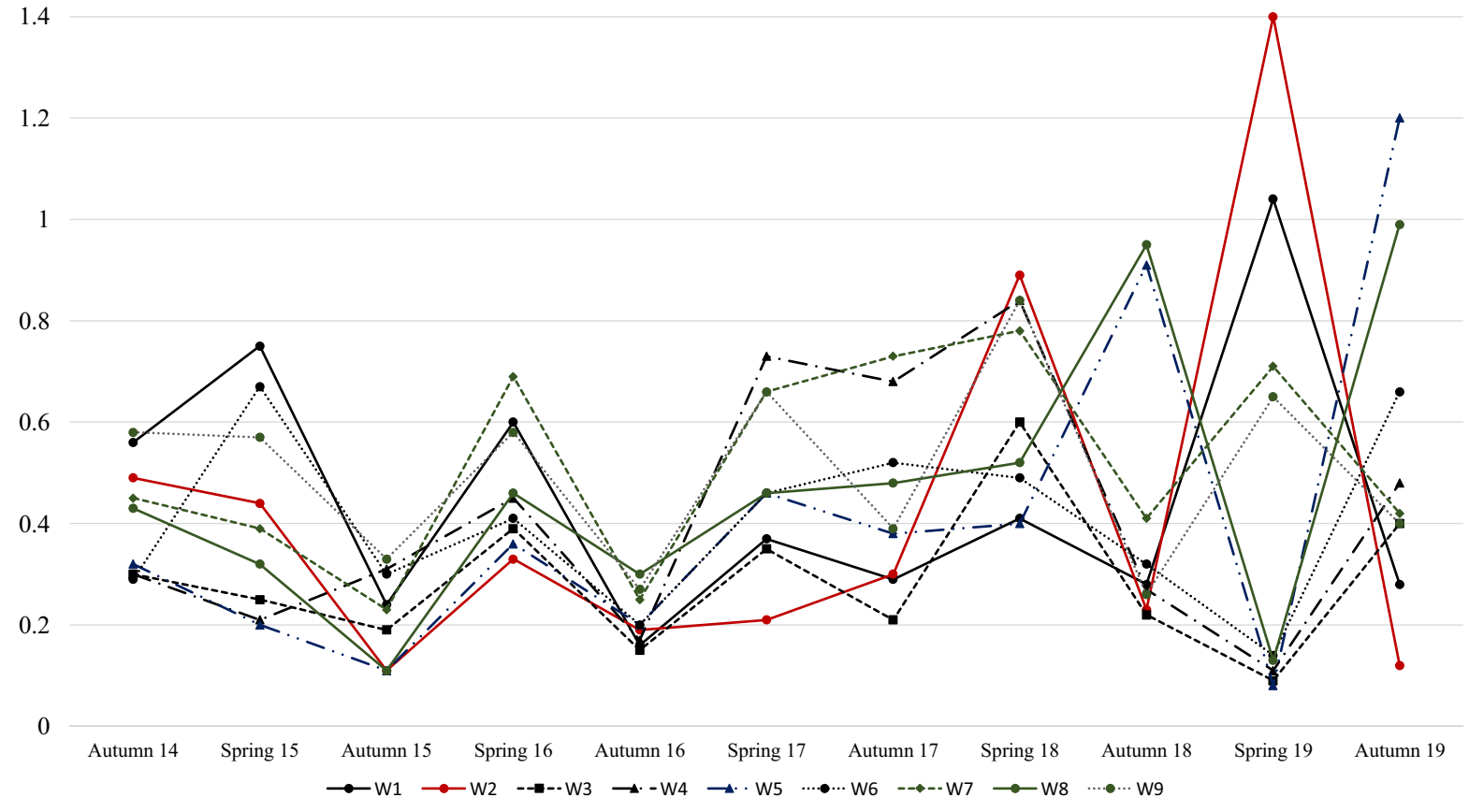

Fig. 6 Temporal variation of a pH, b TPH and $\mathbf{c}$ TDS

$\mathrm{Ca}^{2+}, \mathrm{Mg}^{2+}, \mathrm{Na}^{+}, \mathrm{Cl}^{-}$and $\mathrm{SO}_{4}{ }^{2-}$, on the figure, because they are parts of the TDS and distributed in the same manner (Fig. 7c). Thus, we can consider from the hydrogeological characteristics of this site (Fig. 4) and spatial distribution of $\mathrm{pH}$ and pollutants (Fig. 7) that groundwater flow has a slope toward western direction from the pond. 
(c)

TDS, mg/L

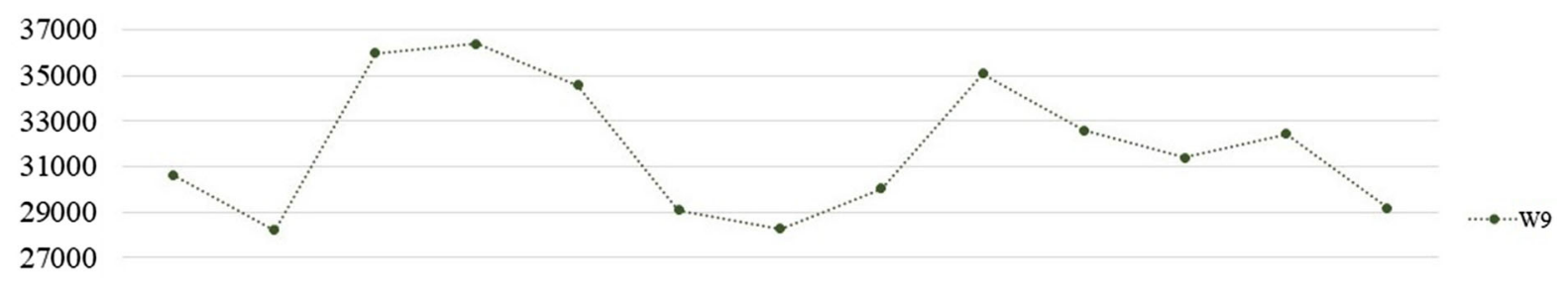

25000

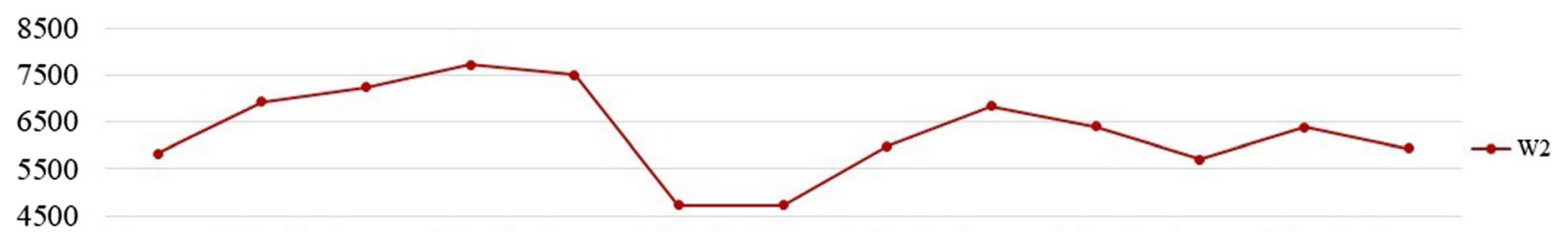

3000

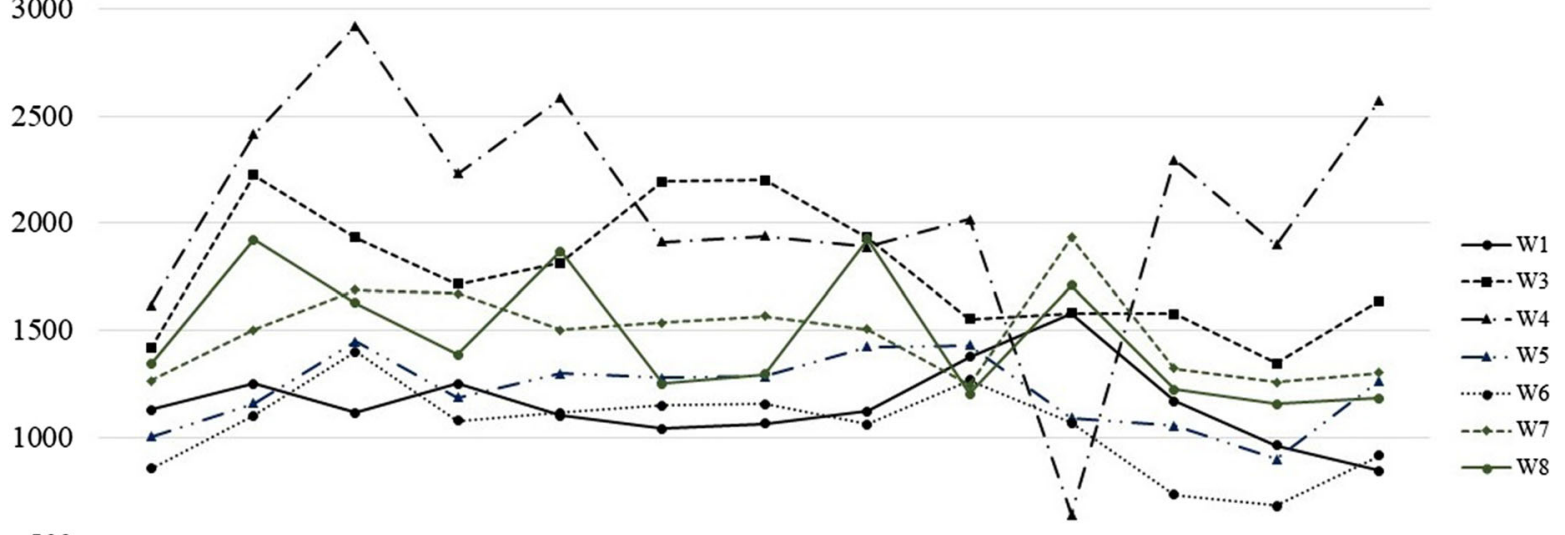

500

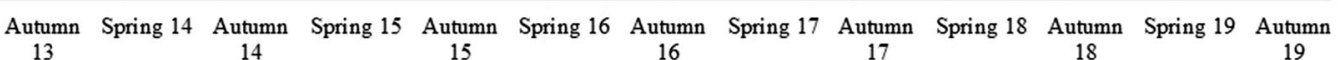

Fig. 6 continued

Principal component analysis

The correlation matrix (Table 3) was employed for all 117 measurements for determining the loads of the principal components (PCs) shown in Table 2. The first six PCs were selected for the following reasons as variables of dimensionality reduction: the six PCs together gave a cumulative contribution of $78.34 \%$, which is typically regarded as being sufficiently high; the eigenvalues of these PCs are all greater than 1.0 and, according to the Kaiser criterion these PCs must be chosen (Table 2) (Kaiser 1958). The factors can be conditionally divided into two groups. First group accounts to $52.34 \%$ of the total variance and is represented by Factors 1 and 2. Usually, the parameters, belonging to those factors, characterize natural conditions of the groundwater. Factors 3-6 contribute to $26 \%$ of the total variance and can be categorized, as anthropogenically appeared factors. The detailed interpretation of each Factor is explained below.

\section{PC 1}

PC 1 explains $42.02 \%$ of the total variance (Table 2). It is characterized by high positive weight values $\mathrm{TH}$, $\mathrm{Ca}^{2+}, \mathrm{Mg}^{2+}, \mathrm{TDS}, \mathrm{Na}^{+}, \mathrm{K}^{+}, \mathrm{Cl}^{-}, \mathrm{SO}_{4}{ }^{2-}$ and surfactants. As Table 3 indicates, there is a strong positive correlation between TDS and $\mathrm{Ca}^{2+}, \mathrm{Mg}^{2+}, \mathrm{Na}^{+}, \mathrm{K}^{+}$, $\mathrm{SO}_{4}{ }^{2-}, \mathrm{Cl}^{-}$. These ions are the major contributors to the total dissolved solids. Additionally, these ions correlate with each other. These results show that the groundwater has suffered serious mineralization 

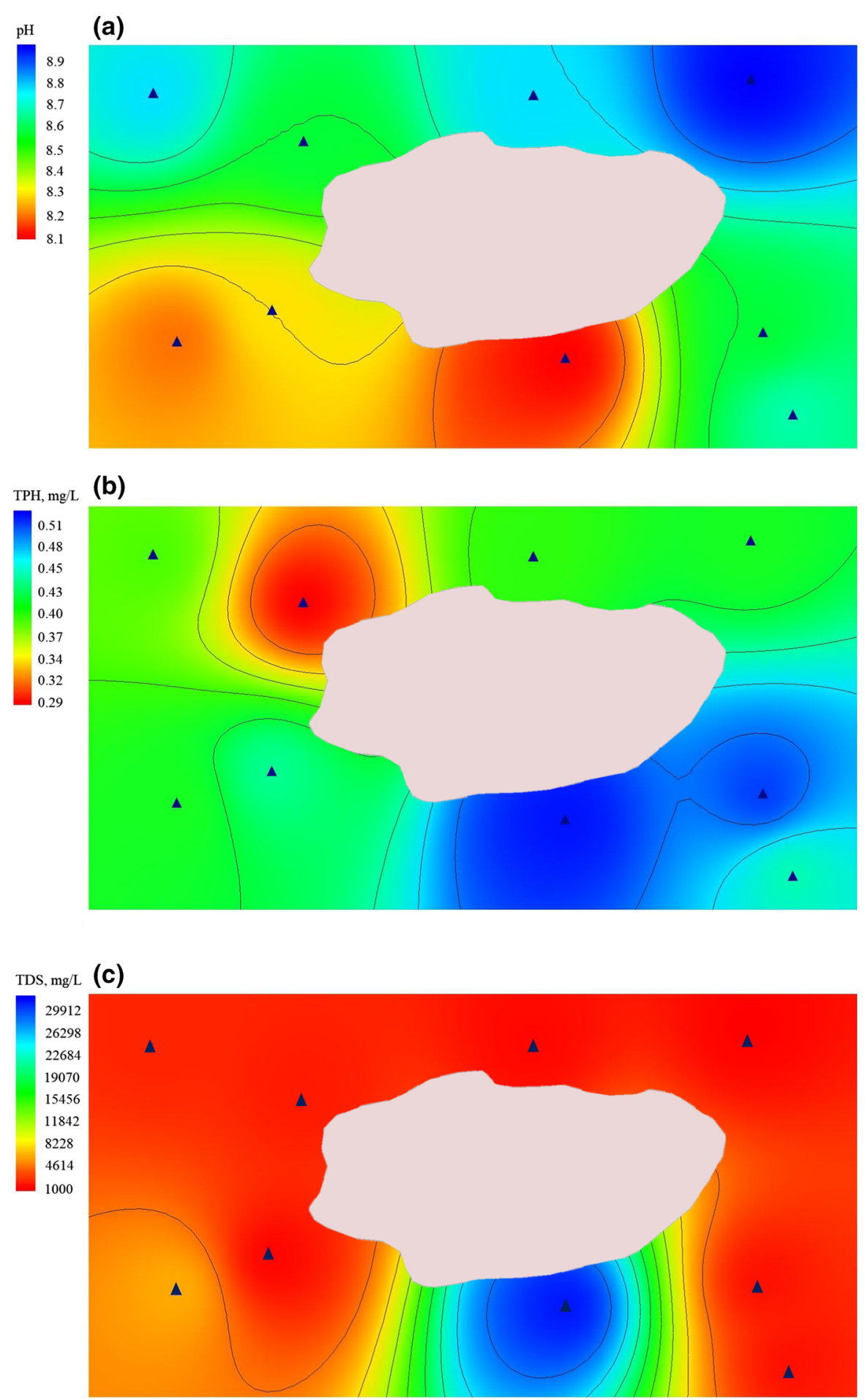

Fig. 7 Spatial distribution patterns of $\mathbf{a} \mathrm{pH}, \mathbf{b}$ TPH and $\mathbf{c}$ TDS 
Fig. 8 Piper diagram for identification of water type of the study area

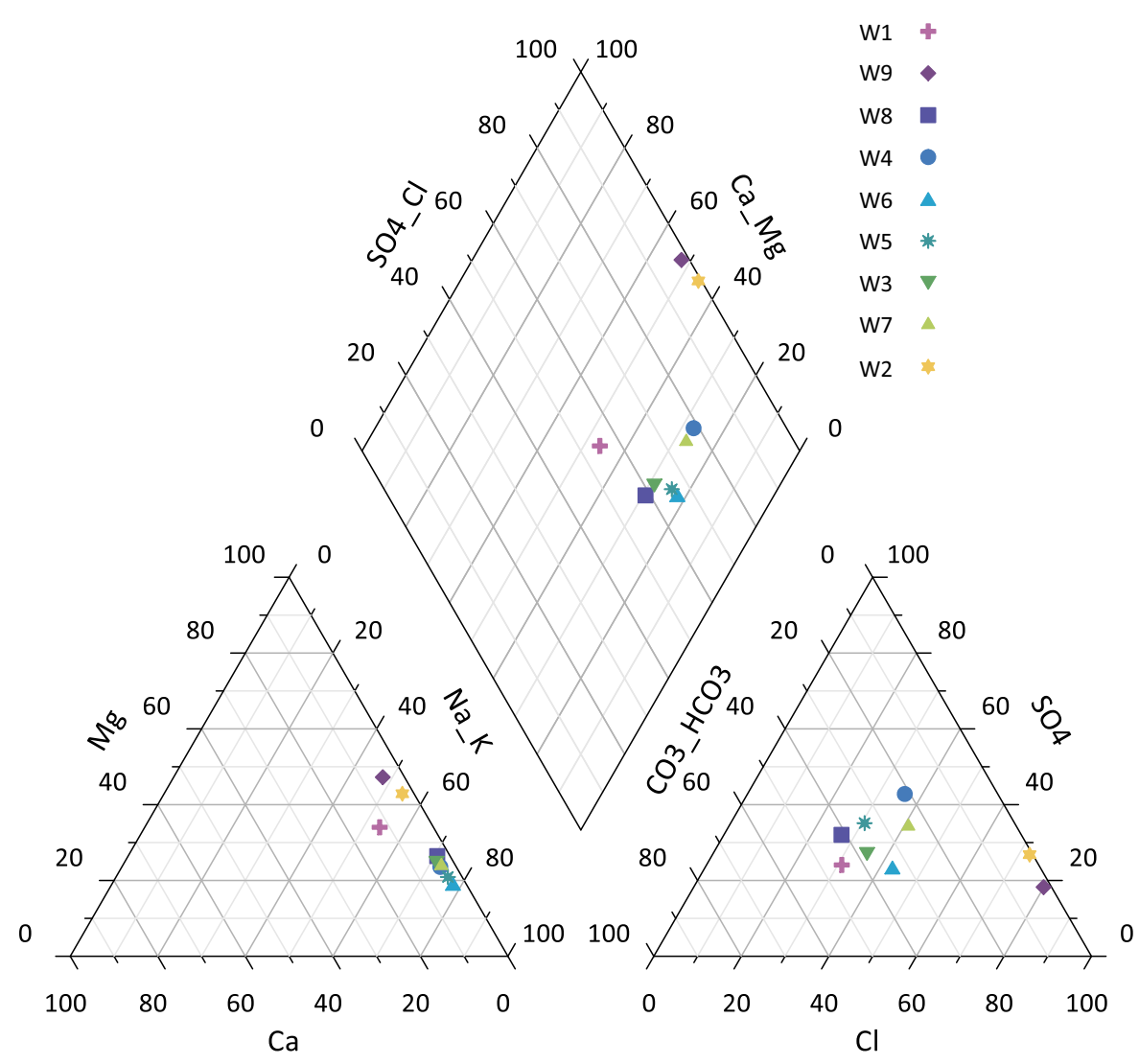

process from the natural condition of the salt pond (Allen and Suchy 2001). Moreover, since TDS correlates with surfactants and surfactants correlate with the above-mentioned ions, it is clear that there is a similarity across parameters.

There also is a clear correlation between $\mathrm{TH}$ and subsequent ions: $\mathrm{Ca}^{2+}, \mathrm{Mg}^{2+}, \mathrm{Cl}^{-}, \mathrm{SO}_{4}{ }^{2-}$ (Table 3). In addition, it can be seen that all these ions correlate with each other. This correlation points to the existence of non-carbonate, or constant hardness, $\left(\mathrm{MeSO}_{4}, \mathrm{MeCl}_{2}\right.$, where $\left.\mathrm{Me}-\mathrm{Ca}, \mathrm{Mg}\right)$, which is difficult to remove. It is clear from Table 3 that there is no correlation between carbonate ions and the hardness metals ions, which suggests a weak temporary hardness. This factor can be explained by the natural conditions of the site. In contrast, surfactants are synthetic compounds. Surfactants are produced for cleaning and washing operations (West and Harwell 1992). Their existence in groundwater is not natural.
$P C 2$

PC 2 explains $10.32 \%$ of the total variance (Table 2) with negative weight values of $\mathrm{pH}$ and $\mathrm{CO}_{3}{ }^{2-}$, and positive value of $\mathrm{CO}_{2}$. It is important to note a correlation between $\mathrm{CO}_{2}, \mathrm{CO}_{3}{ }^{2-}$ and $\mathrm{pH}$ (Table 3), which points to alkalinity reactions in the groundwater (Eq. 6). The relationship exists between these parameters and $\mathrm{CO}_{2}$, which potentially could be described a process of $\mathrm{CO}_{2}$ creation or the presence of the $\mathrm{CO}_{2}$ as an atmospheric gas in the unsaturated zone (Hem 1970). Moreover, the high concentration of chlorides in wastewater coupled with the natural salt water leads to changing $\mathrm{pH}$ in groundwater by decreasing $\mathrm{pH}$. These processes are naturally based.

$\mathrm{Alk}=2\left[\mathrm{CO}_{3}^{2-}\right]+\left[\mathrm{HCO}_{3}^{-}\right]+\left[\mathrm{OH}^{-}\right]-\left[\mathrm{H}^{+}\right]$.

\section{$P C 3$}

Factor 3 is characterized by a positive value of nitrite ion (Table 2) and contributes $7.68 \%$ to the total 
Table 2 Factor loadings (Varimax normalized)

\begin{tabular}{|c|c|c|c|c|c|c|}
\hline \multirow[b]{2}{*}{ Variable } & \multicolumn{2}{|l|}{ Natural } & \multicolumn{4}{|c|}{ Anthropogenic } \\
\hline & Factor (1) & Factor (2) & Factor (3) & Factor (4) & Factor (5) & Factor (6) \\
\hline $\mathrm{pH}$ & -0.233 & -0.900 & -0.045 & 0.042 & 0.023 & 0.014 \\
\hline TPH & 0.102 & -0.034 & -0.267 & 0.746 & -0.024 & -0.201 \\
\hline TDS & 0.924 & 0.205 & 0.171 & 0.158 & -0.002 & -0.058 \\
\hline $\mathrm{Cl}^{-}$ & 0.888 & 0.251 & 0.203 & 0.146 & -0.086 & -0.058 \\
\hline $\mathrm{SO}_{4}{ }^{2-}$ & 0.927 & 0.086 & 0.203 & 0.063 & 0.041 & -0.046 \\
\hline $\mathrm{NH}_{4}^{+}$ & 0.289 & -0.045 & 0.198 & 0.783 & -0.051 & 0.162 \\
\hline $\mathrm{NO}_{2}^{-}$ & 0.254 & -0.059 & 0.797 & -0.075 & -0.173 & -0.004 \\
\hline $\mathrm{NO}_{3}{ }^{-}$ & 0.514 & 0.012 & 0.500 & -0.031 & 0.363 & 0.121 \\
\hline $\mathrm{PO}_{4}{ }^{3-}$ & -0.100 & 0.041 & 0.012 & -0.039 & 0.027 & 0.886 \\
\hline $\mathrm{CO}_{3}{ }^{2-}$ & -0.140 & -0.692 & -0.074 & -0.010 & -0.023 & -0.337 \\
\hline $\mathrm{HCO}_{3}{ }^{-}$ & -0.297 & -0.159 & -0.120 & 0.026 & 0.460 & 0.208 \\
\hline $\mathrm{TH}$ & 0.927 & 0.160 & 0.147 & 0.188 & 0.053 & -0.033 \\
\hline $\mathrm{Ca}^{2+}$ & 0.729 & -0.069 & -0.382 & -0.182 & -0.231 & 0.092 \\
\hline $\mathrm{Mg}^{2+}$ & 0.798 & 0.215 & 0.326 & 0.313 & 0.085 & -0.050 \\
\hline $\mathrm{K}^{+}$ & 0.807 & -0.032 & -0.375 & -0.106 & 0.008 & 0.039 \\
\hline $\mathrm{Na}^{+}$ & 0.931 & 0.150 & 0.196 & 0.133 & -0.004 & -0.045 \\
\hline Surfactants & 0.732 & 0.131 & 0.107 & 0.165 & 0.085 & -0.116 \\
\hline $\mathrm{CO}_{2}$ & 0.094 & 0.845 & -0.133 & -0.025 & -0.013 & -0.165 \\
\hline Phenol & 0.196 & 0.078 & -0.015 & -0.077 & 0.873 & -0.086 \\
\hline Eigenvalue & 7.984 & 1.960 & 1.458 & 1.307 & 1.160 & 1.015 \\
\hline$\%$ of variance & 42.023 & 10.315 & 7.676 & 6.881 & 6.105 & 5.340 \\
\hline Cumulative $\%$ & 42.023 & 52.337 & 60.013 & 66.894 & 73.000 & 78.339 \\
\hline
\end{tabular}

variance. $\mathrm{NO}_{2}{ }^{-}$does not correlate with any chemicals. The presence of the parameter could be explained as a semi-product of the natural denitrification/deammonification processes in the groundwater environment according to Hisckock et al. (1991).

PC 4

TPH and ammonia ion represent PC 4 and account for $6.89 \%$ of the total contamination (Table 2). Both chemicals have no correlation according Table 3, which shows their independence on the other variables. This level of petroleum hydrocarbons in drinking water can lead to damage of the nervous system and carcinogen and narcotic effects associated caused by some hydrocarbons (Logeshwaran et al. 2018). In addition, even a few micrograms of TPH per litre deteriorate the odour and taste of the contaminated water. The high loading of $\mathrm{NH}_{4}{ }^{+}$is associated with extremally high concentrations of ammonia in discharges (Radelyuk et al. 2019). Hence, the amount of ammonia is not degraded during the saturation processes and some traces still presence in the groundwater. This factor is certainly attributed to groundwater pollution from the petrochemical industry.

PC 5

PC 5 is characterized by positive value of phenols (Table 2), which accounts for $6.11 \%$ of the whole contamination. This parameter is characterized as a very toxic pollutant. Concentrations of the phenolic compounds probably exceed the permissible level (Table 1); the exposure is evaluated as a potential risk for public health. The loading of this parameter is directly related to the specification of petrochemical wastewater. 


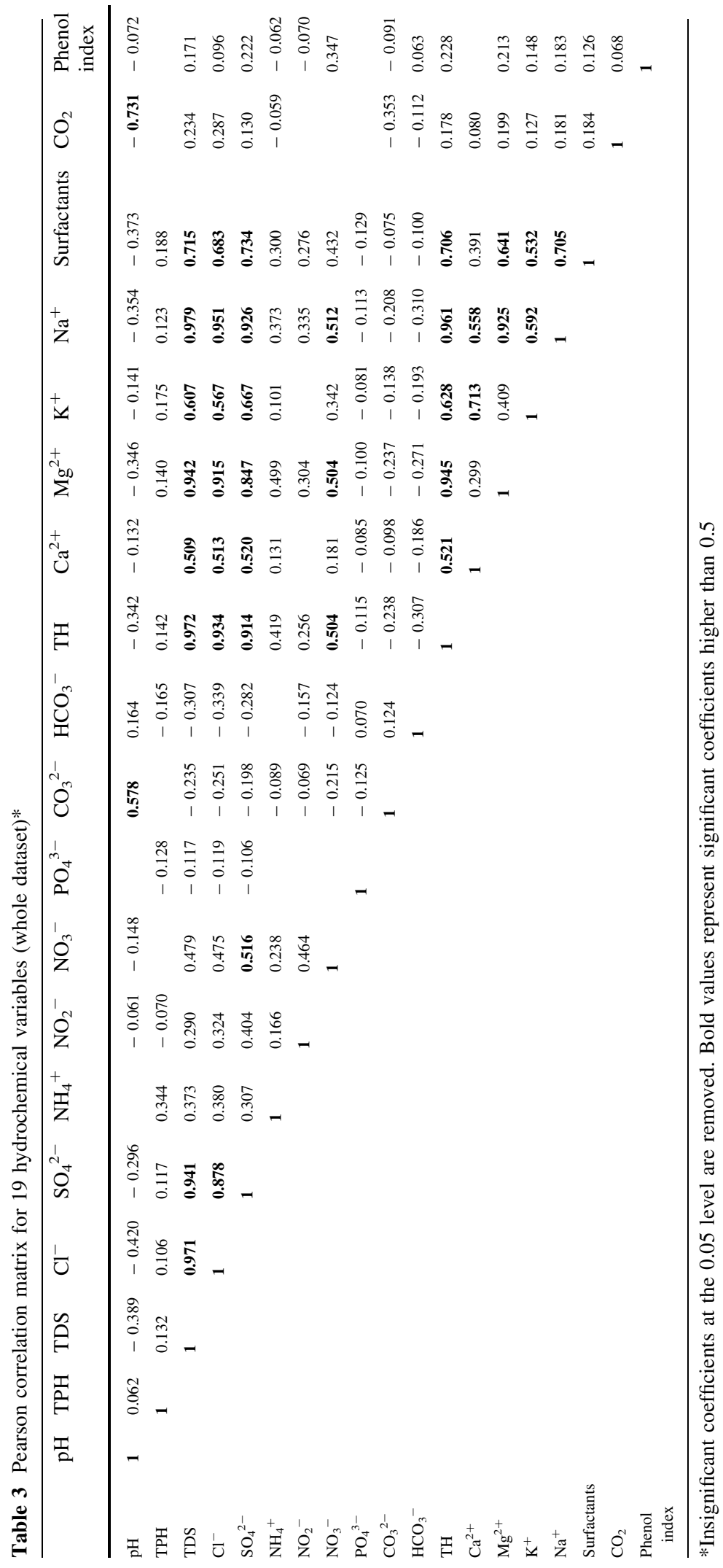


PC 6

One more significant factor belongs to the influence of phosphate-ions and is rated by $5.34 \%$ of the total variance (Table 2). It should be pointed out that the enterprise does not provide monitoring of phosphate concentration in the discharges. Nevertheless, the refining process is associated with a vast number of washing processes, which leads to big consumption of different detergents, which contain phosphate substances. As the rocks and fertilizers are absent in the study area (Rao and Prasad 1997), we can conclude that the loading of the contaminant is an indicator of anthropogenic impact on the groundwater.

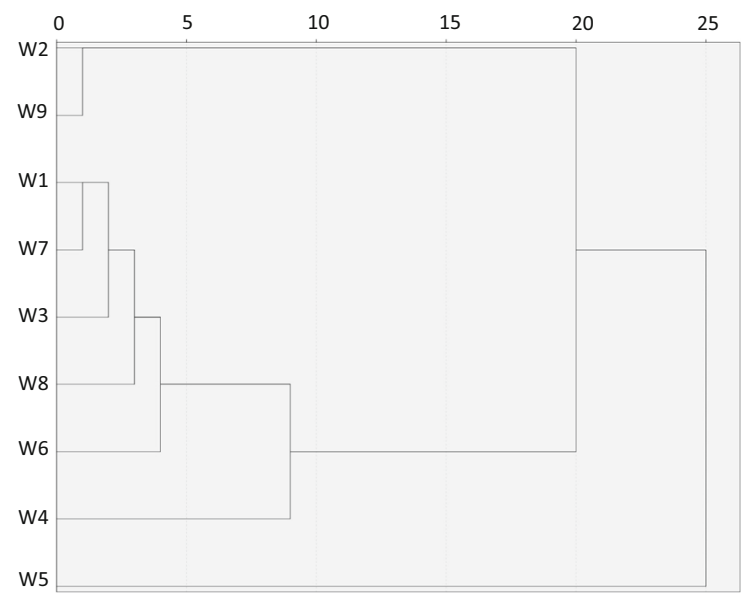

Fig. 9 Dendrogram showing clustering of sampling sites according to groundwater characteristics (Ward Linkage. Euclidean Distance)

Table 4 Selected variables characteristics*

\begin{tabular}{lll}
\hline Variable & Toxic & Non-toxic \\
\hline Number of observations & 324 & 351 \\
& $48.0 \%$ & $52.0 \%$ \\
Number (\%) of exceeded values & $255(78.7)$ & $248(70.7)$ \\
$\begin{array}{l}\text { Dependent variables } \\
\text { Toxic contaminant }\end{array}$ & 1.0 & 0.0 \\
$\%$ of exceeding & $664(1042)$ & $862(1526)$ \\
\hline
\end{tabular}

* Statistics of chosen chemicals is available from Table 1
Cluster analysis

Based on the performed CA and results above, the study area was divided into three clusters. Figure 9 shows a dendrogram of all nine sampling sites into three statistically meaningful clusters yielded by cluster analysis. Cluster 1 combines observed wells W9 and W2. These wells are labelled as highly contaminated with the highest exceeding of many chemical parameters. Figure $4 \mathrm{a}$ shows their similarities in the distribution of $\mathrm{pH}$, which is followed by host geology. The wells are situated on the southwest site from the pond and probably approve an assumption about direction of groundwater flow. Cluster 2 is formed by wells W7, W8, W1 and W3. These wells are located on the south and west sides of the pond and characterized by twofold characteristics: firstly, significant pollution rate, including the same concentrations of the TDS and TDS related chemicals and secondly, the equal temporal distribution of $\mathrm{pH}$. It means that groundwater on that site is affected by pollutant transport from the pond in the same manner. Finally, Cluster 3 is represented by wells W6, W4 and W5. All wells are located north of the pond and are characterized by lower concentrations of the pollutants compared to other wells. We may consider that groundwater flow originates from east to west, and potential hazard exists for rural inhabitants towards to west and south-west direction from the pond.

\section{The Heckman selection model}

This study uses the Heckman selection model to estimate relationships between total contamination and other characteristics, especially, significance of toxicity rate. If we adapt Eqs. (4) and (5) for our case

Table 5 Estimated results of the Heckman selection model (two-step) for selected chemicals

\begin{tabular}{lcll}
\hline Variable & Coefficient & Std. Err & Z-statistic \\
\hline Chemical & -0.156 & 0.074 & -2.11 \\
Concentration & 1.576 & 0.260 & 6.07 \\
Toxicity rate & 0.789 & 0.245 & 3.22 \\
Number of well & 0.020 & 0.025 & 0.83 \\
Rho & 1.0 & & \\
\hline
\end{tabular}


according Stata manual (STATA 2013), we can represent the equations respectively as:

$\%$ of exceeding $=\beta_{1}$ chemical $+\beta_{2}$ concentration

$$
+u_{i}
$$

and we assumed that " $\%$ of exceeding" is estimated if

$\gamma_{1}$ toxicity $+\gamma_{2}$ number of well $+\gamma_{3}$ chemical $\gamma_{4}$

+ concentration $+v_{i}>0$,

where $u i$ and $v i$ have positive correlation $\rho$.

Table 4 shows the selected variables used in this analysis and their descriptive statistics. The first dependent variable $\left(D_{i}\right)$ represents toxicity of the chosen chemical. The value equals 1 if the pollutant is toxic and 0 if not. The second set of dependent variables $\left(Y_{i}\right)$ includes percentage of exceeding. This characteristic mathematically represents rate of contamination. Mean percentage of selected (toxic or nontoxic) exceeding was calculated. For example, if the concentration of TPH measurement was $0.25 \mathrm{mg} / \mathrm{L}$, but standard value is no more than $0.1 \mathrm{mg} / \mathrm{L}$, then dependent variable equals $250 \%$. This variable includes only exceeded values. Otherwise, if the value is normal, a cell in a matrix is empty. Numbers in parentheses are standard deviations of the average values. Set of control variables $\left(X_{i}\right)$ includes chosen contaminants, their concentrations and locations. According requirements (Kazakhstan 2015), TH, $\mathrm{TPH}$, and $\mathrm{Na}^{+}$are considered as hazardous for public health and rated with value 1.0 for the variable $D_{i}$. TDS, sulphates and chlorides are considered as nontoxic and were rated as value 0.0 for the variable $D_{i}$. We encrypted TDS, $\mathrm{Cl}^{-}, \mathrm{SO}_{4}{ }^{2-}, \mathrm{Na}^{+}, \mathrm{TH}$ and TPH in the table of variables as "1", "2", " 3 ", " 4 ", " 5 " and " 6 ", respectively. The contaminants are not a subject for assessment in this analysis.

Table 5 presents the estimation for this type of analysis. Rho has a positive value, which means that it is possible to estimate relationships between chosen variables and final contamination. All variables, excluding number of well (which represents location of the wells), are considered as significant. The concentration of pollutants has the greatest influence on total contamination. Positive value explains likelihood of potential hazard for people health. Obviously, the high concentrations of the pollutants lead to deterioration of health, especially during long-term exposure. In our case, 503 of 675 values exceed acceptable limits by $7-8$ times averagely. The variable of toxicity rate is the second significant factor. This variable reflects to lower percentage of exceedings for toxic contaminants than for non-toxic, instead of higher number of exceeded values for toxic contaminants than non-toxic. Our hypothesize assumes that even if the concentration of the toxic contaminant exceeds the standard by just a few units, the toxic properties could be much more dangerous for human health, compared with the consumption of highly polluted water by non-toxic contaminants. The independent chemicals represent the third significant variable. Individual characteristics of chosen chemicals are explained in sub-section "Groundwater quality parameters". The location of the well is rated as not significant parameter. Nevertheless, the investigation of hydrogeological characteristics deserves attention in the future work and determines the spread of contamination.

\section{Conclusions}

This study investigated the current situation of groundwater safety for public health surrounding a contaminated site in Kazakhstan. The results show that PCAs have high loading of anthropogenic contamination to groundwater from the oil refinery industry coupled with natural geochemical processes. In addition, exceeding concentrations of hazardous substances, including TPH, phenols, TH, and TDS were identified. By means of cluster analysis we were able to combine the examined wells in three groups according to the concentrations of chemicals and their locations. Highly polluted groundwater was distributed especially in west and south-west direction from the pond. The results enable the prediction of the groundwater flow in the study area as well as the estimation of sites heavily affected by contamination. The usage of Heckman selection model, to the authors' knowledge, is the first attempt in the literature, applied to evaluation of environmental factors. According to obtained data from Heckman analysis, focus should be paid to the distribution of toxic contaminants.

For this purpose, further research considers: (1) Groundwater modelling for definite identification of groundwater flow and potentially affected rural areas; 
(2) Contamination transport modelling, as the industry continue polluting the environment, the assessment of present and future hazards is highly needed; (3) Development of a remediation plan, which has to be built on the qualitative studies (1) and (2).

This study might be used as a trigger to drive and engage all stakeholders into the transparent dialogue about potential consequences of non-sustainable wastewater management at oil refinery industry. The potential actions might include implementation of successful legislative standards, development of new efficient monitoring programs, stimulation the industry to innovative and water-saving treatment methods and a creation of a site contamination/remediation programs.

This research has several limitations. Firstly, the limited dataset covers only period from 2013 to 2019 . Secondly, despite of the concentrations of TPH are identified, the lack of data on specific hydrocarbon type such as PAH and BTEX limited the analysis on the toxicity. Thirdly, the lack of access to hydrogeological data limited the accuracy of the ground water flow estimation. Authors of this paper recommend initiating a dialogue between industry, government, and academia for research-based decision-making in this area.

Acknowledgments Open access funding provided by Lund University. Åke och Greta Lissheds stiftelse supported this research (Reference ID: 2019-00112). The first author was funded by Bolashak International Scholarship Program of Kazakhstan.

\section{Compliance with ethical standards}

Conflicts of interest The authors declare no conflict of interest.

Open Access This article is licensed under a Creative Commons Attribution 4.0 International License, which permits use, sharing, adaptation, distribution and reproduction in any medium or format, as long as you give appropriate credit to the original author(s) and the source, provide a link to the Creative Commons licence, and indicate if changes were made. The images or other third party material in this article are included in the article's Creative Commons licence, unless indicated otherwise in a credit line to the material. If material is not included in the article's Creative Commons licence and your intended use is not permitted by statutory regulation or exceeds the permitted use, you will need to obtain permission directly from the copyright holder. To view a copy of this licence, visit http://creativecommons.org/licenses/by/4.0/.

\section{References}

Allen, D., \& Suchy, M. (2001). Geochemical evolution of groundwater on Saturna Island, British Columbia. Canadian Journal of Earth Sciences, 38(7), 1059-1080. https:// doi.org/10.1139/e01-007.

Amanah, T., Putranto, T., \& Helmi, M. Application of cluster analysis and principal component analysis for assessment of groundwater quality-A study in Semarang, Central Java, Indonesia. In IOP conference series: earth and environmental science, 2019 (Vol. 248, pp. 012063). IOP Publishing.

Angelino, S., \& Gennaro, M. C. (1997). An ion-interaction RPHPLC method for the determination of the eleven EPA priority pollutant phenols. Analytica Chimica Acta, 346(1), 61-71. https://doi.org/10.1016/S0003-2670(97)00124-4.

Awomeso, J. A., Ahmad, S. M., \& Taiwo, A. M. (2020). Multivariate assessment of groundwater quality in the basement rocks of Osun State, Southwest. Nigeria. Environmental Earth Sciences. https://doi.org/10.1007/ s12665-020-8858-z.

Bekturganov, Z., Tussupova, K., Berndtsson, R., Sharapatova, N., Aryngazin, K., \& Zhanasova, M. (2016). Water related health problems in Central Asia-a review. Water, 8, 6. https://doi.org/10.3390/w8060219.

Bouteraa, O., Mebarki, A., Bouaicha, F., Nouaceur, Z., \& Laignel, B. (2019). Groundwater quality assessment using multivariate analysis, geostatistical modeling, and water quality index (WQI): a case of study in the Boumerzoug-El Khroub valley of Northeast Algeria. Acta Geochimica, 38(6), 796-814. https://doi.org/10.1007/s11631-01900329-x.

BP (2018). BP Statistical review of world energy. https://www. bp.com/content/dam/bp/business-sites/en/global/ corporate/pdfs/energy-economics/statistical-review/bpstats-review-2018-full-report.pdf.

Cloutier, V., Lefebvre, R., Therrien, R., \& Savard, M. M. (2008). Multivariate statistical analysis of geochemical data as indicative of the hydrogeochemical evolution of groundwater in a sedimentary rock aquifer system. Journal of Hydrology, 353(3-4), 294-313. https://doi.org/10.1016/ j.jhydrol.2008.02.015.

Egbueri, J. C. (2019). Evaluation and characterization of the groundwater quality and hydrogeochemistry of Ogbaru farming district in southeastern Nigeria. Sn Applied Sciences. https://doi.org/10.1007/s42452-019-0853-1.

EPA. (2012). Ambient water quality criteria for phenol. https:// www.epa.gov/sites/production/files/2019-03/documents/ ambient-wqc-phenol-1980.pdf.

Gadgil, A. (1998). Drinking water in developing countries. Annual Review of Energy and the Environment, 23, 253-286. https://doi.org/10.1146/annurev.energy.23.1. 253.

Ghahremanzadeh, H., Noori, R., Baghvand, A., \& Nasrabadi, T. (2018). Evaluating the main sources of groundwater pollution in the southern Tehran aquifer using principal component factor analysis. Environmental Geochemistry and Health, 40(4), 1317-1328. https://doi.org/10.1007/ s10653-017-0058-8. 
Heaven, S., Banks, C. J., Pak, L. N., \& Rspaev, M. K. (2007). Wastewater reuse in central Asia: Implications for the design of pond systems. Water Science and Technology, 55(1-2), 85-93. https://doi.org/10.2166/wst.2007.061.

Heckman, J. J. (1979). Sample selection bias as a specification error. Econometrica, 47(1), 153-161. https://doi.org/10. 2307/1912352.

Hem, J. D. (1970). Study and interpretation of the chemical characteristics of natural water (Vol. 1473): US Government Printing Office.

Hiscock, K. M., Lloyd, J. W., \& Lerner, D. N. (1991). Review of natural and artificial denitrification of groundwater. Water Research, 25(9), 1099-1111. https://doi.org/10.1016/ 0043-1354(91)90203-3.

Houlihan, M. F., \& Lucia, P. C. (1999). Groundwater monitoring. In J. W. Delleur (Ed.), The Handbook of Groundwater Engineering. Boca Raton, FL: CRC Press.

Kaiser, H. F. (1958). The varimax criterion for analytic rotation in factor-analysis. Psychometrika, 23(3), 187-200. https:// doi.org/10.1007/Bf02289233.

Kaplan, S., Nielsen, T. A. S., \& Prato, C. G. (2016). Walking, cycling and the urban form: A Heckman selection model of active travel mode and distance by young adolescents. Transportation Research Part D-Transport and Environment, 44, 55-65. https://doi.org/10.1016/j.trd.2016.02.011.

Karatayev, M., Kapsalyamova, Z., Spankulova, L., Skakova, A., Movkebayeva, G., \& Kongyrbay, A. (2017). Priorities and challenges for a sustainable management of water resources in Kazakhstan. Sustainability of Water Quality and Ecology, 9-10, 115-135. https://doi.org/10.1016/j.swaqe. 2017.09.002.

Kazakhstan. (2012). Order №110 of the Minister of the Environment "On approval of the methodology for determining emission standards for the environment". https://adilet. zan.kz/rus/docs/V1200007664.

Kazakhstan. (2015). Sanitary and epidemiological requirements for water sources, water intake points for household and drinking purposes, domestic and drinking water supply and places of cultural and domestic water use and water safety. https://adilet.zan.kz/rus/docs/V1500010774.

Kazi, T. G., Arain, M. B., Jamali, M. K., Jalbani, N., Afridi, H. I., Sarfraz, R. A., et al. (2009). Assessment of water quality of polluted lake using multivariate statistical techniques: A case study. Ecotoxicology and Environmental Safety, 72(2), 301-309. https://doi.org/10.1016/j.ecoenv.2008.02. 024.

Kovalick, W. W., \& Montgomery, R. H. (2017). Models and lessons for developing a contaminated site program: An international review. Environmental Technology \& Innovation, 7, 77-86. https://doi.org/10.1016/j.eti.2016.12.005.

Li, Q., Zhang, H., Guo, S., Fu, K., Liao, L., Xu, Y., et al. (2019). Groundwater pollution source apportionment using principal component analysis in a multiple land-use area in southwestern China. Environmental Science and Pollution Research. https://doi.org/10.1007/s11356-019-06126-6.

Liu, C. W., Lin, K. H., \& Kuo, Y. M. (2003). Application of factor analysis in the assessment of groundwater quality in a blackfoot disease area in Taiwan. Science of the Total Environment, 313(1-3), 77-89. https://doi.org/10.1016/ S0048-9697(02)00683-6.
Logeshwaran, P., Megharaj, M., Chadalavada, S., Bowman, M., \& Naidu, R. (2018). Petroleum hydrocarbons (PH) in groundwater aquifers: An overview of environmental fate, toxicity, microbial degradation and risk-based remediation approaches. Environmental Technology \& Innovation, 10, 175-193. https://doi.org/10.1016/j.eti.2018.02.001.

Lucas, L., Riddell, L., Liem, G., Whitelock, S., \& Keast, R. (2011). The influence of sodium on liking and consumption of salty food. Journal of Food Science, 76(1), S72-S76. https://doi.org/10.1111/j.1750-3841.2010.01939.x.

Maskooni, E. K., Naseri-Rad, M., Berndtsson, R., \& Nakagawa, K. (2020). Use of heavy metal content and modified water quality index to assess groundwater quality in a semiarid area. Water, 12(4), 1115. https://doi.org/10.3390/ w12041115.

Nair, C. I., Jayachandran, K., \& Shashidhar, S. (2008). Biodegradation of phenol. African Journal of Biotechnology, 7(25), 4951-4958. https://doi.org/10.5897/AJB08. 087.

Naseh, M. R. V., Noori, R., Berndtsson, R., Adamowski, J., \& Sadatipour, E. (2018). Groundwater pollution sources apportionment in the Ghaen Plain, Iran. International Journal of Environmental Research and Public Health, 15, 1. https://doi.org/10.3390/ijerph15010172.

Naseri Rad, M., \& Berndtsson, R. (2019). Shortcomings in current practices for decision-making process and contaminated sites remediation. The 5th World Congress on New Technologies, https://doi.org/10.11159/ICEPR19. 155 .

Naseri Rad, M., Berndtsson, R., Persson, K. M., \& Nakagawa, K. (2020). INSIDE: An efficient guide for sustainable remediation practice in addressing contaminated soil and groundwater. Science of the Total Environment. https://doi. org/10.1016/j.scitotenv.2020.139879.

Noori, R., Sabahi, M. S., Karbassi, A. R., Baghvand, A., \& Zadeh, H. T. (2010). Multivariate statistical analysis of surface water quality based on correlations and variations in the data set. Desalination, 260(1-3), 129-136. https:// doi.org/10.1016/j.desal.2010.04.053.

Omo-Irabor, O. O., Olobaniyi, S. B., Oduyemli, K., \& Alunna, J. (2008). Surface and groundwater water quality assessment using multivariate analytical methods: A case study of the Western Niger Delta, Nigeria. Physics and Chemistry of the Earth, 33(8-13), 666-673. https://doi.org/10.1016/j. pce.2008.06.019.

Patil, V. B. B., Pinto, S. M., Govindaraju, T., Hebbalu, V. S., Bhat, V., \& Kannanur, L. N. (2020). Multivariate statistics and water quality index (WQI) approach for geochemical assessment of groundwater quality-a case study of Kanavi Halla Sub-Basin, Belagavi, India. Environmental Geochemistry and Health, 1-18.

Pinedo, J., Ibanez, R., Lijzen, J. P. A., \& Irabien, A. (2013). Assessment of soil pollution based on total petroleum hydrocarbons and individual oil substances. Journal of Environmental Management, 130, 72-79. https://doi.org/ 10.1016/j.jenvman.2013.08.048.

Piper, A. M. (1944). A graphic procedure in the geochemical interpretation of water-analyses. Transactions-American Geophysical Union, 25, 914-923. https://doi.org/10.1029/ tr025i006p00914. 
Radelyuk, I., Tussupova, K., Zhapargazinova, K., Yelubay, M., \& Persson, M. (2019). Pitfalls of wastewater treatment in oil refinery enterprises in kazakhstan-a system approach. Sustainability. https://doi.org/10.3390/su11061618.

Rao, N. S., \& Prasad, P. R. (1997). Phosphate pollution in the groundwater of lower Vamsadhara river basin, India. Environmental Geology, 31(1-2), 117-122. https://doi.org/ $10.1007 / \mathrm{s} 002540050170$.

Sartori, A. E. (2003). An estimator for some binary-outcome selection models without exclusion restrictions. Political Analysis, 11(2), 111-138. https://doi.org/10.1093/pan/ $\operatorname{mpg} 001$.

Shrestha, S., \& Kazama, F. (2006). Multivariate statistical techniques for the assessment of surface water quality of Fuji River Basin, Japan. 5th World Water Congress: Water Services Management, 6(5), 59-67, doi:https://doi.org/10. 2166/ws.2006.802.

Shrestha, S., \& Kazama, F. (2007). Assessment of surface water quality using multivariate statistical techniques: A case study of the Fuji river basin, Japan. Environmental Modelling \& Software, 22(4), 464-475. https://doi.org/10.1016/ j.envsoft.2006.02.001.

Stambuk-Giljanovic, N., \& Stambuk, D. (2005). Information subsystem of total hardness $(\mathrm{Ca}+\mathrm{Mg})$ as a database for studying its influence on human health. Journal of Medical Systems, 29(6), 671-678. https://doi.org/10.1007/s10916005-6135-z.

STATA. (2013). Heckman selection model. https://www.stata. com/manuals/rheckman.pdf.

Sun, D. Q., Bai, J. F., Qiu, H. G., \& Cai, Y. Q. (2014). Impact of government subsidies on household biogas use in rural China. Energy Policy, 73, 748-756. https://doi.org/10. 1016/j.enpol.2014.06.009.

Trabelsi, R., \& Zouari, K. (2019). Coupled geochemical modeling and multivariate statistical analysis approach for the assessment of groundwater quality in irrigated areas: A study from North Eastern of Tunisia. Groundwater for Sustainable Development, 8, 413-427.

Tussupova, K., Berndtsson, R., Bramryd, T., \& Beisenova, R. (2015). Investigating willingness to pay to improve water supply services: Application of contingent valuation method. Water, 7(6), 3024-3039. https://doi.org/10.3390/ w7063024.

Tussupova, K., Hjorth, P., \& Berndtsson, R. (2016). Access to Drinking Water and Sanitation in Rural Kazakhstan. International Journal of Environmental Research and Public Health, 13, 1. https://doi.org/10.3390/ijerph13111115.

UN. (2019). FAO UN. Country Fact Sheet. Kazakhstan. https:// www.fao.org/nr/water/aquastat/data/cf/readPdf.html?f= KAZ-CF_eng.pdf.

UNECE. (2019). Environmental performance review for Kazakhstan. https://www.unece.org/fileadmin/DAM/env/ epr/epr_studies/ECE_CEP_185_Eng.pdf.

UNESCO. (2015). Water for a sustainable world. Facts and figures. https://www.unesco.org/new/fileadmin/ MULTIMEDIA/HQ/SC/images/WWDR2015Facts_ Figures_ENG_web.pdf.

Wake, H. (2005). Oil refineries: A review of their ecological impacts on the aquatic environment. Estuarine Coastal and Shelf Science, 62(1-2), 131-140. https://doi.org/10.1016/j. ecss.2004.08.013.

West, C. C., \& Harwell, J. H. (1992). Surfactants and subsurface remediation. Environmental Science \& Technology, 26(12), 2324-2330. https://doi.org/10.1021/es00036a002.

WHO. (2006). Protecting groundwater for health: Managing the quality of drinking-water sources. (Vol. 1, pp. 310).

WHO (2017). Guidelines for drinking-water quality https:// apps.who.int/iris/bitstream/handle/10665/254637/ 9789241549950-eng.pdf? sequence $=1$.

Xu, X. C., Wong, S. C., Zhu, F., Pei, X., Huang, H. L., \& Liu, Y. J. (2017). A Heckman selection model for the safety analysis of signalized intersections. PLOS ONE. https://doi. org/10.1371/journal.pone.0181544.

Zhupankhan, A., Tussupova, K., \& Berndtsson, R. (2018). Water in Kazakhstan, a key in Central Asian water management. Hydrological Sciences Journal-Journal Des Sciences Hydrologiques, 63(5), 752-762. https://doi.org/ 10.1080/02626667.2018.1447111.

Publisher's Note Springer Nature remains neutral with regard to jurisdictional claims in published maps and institutional affiliations. 